\title{
Simulating secondary organic aerosol in a regional air quality model using the statistical oxidation model - Part 2: Assessing the influence of vapor wall losses
}

\author{
Christopher D. Cappa ${ }^{1}$, Shantanu H. Jathar ${ }^{2}$, Michael J. Kleeman ${ }^{1}$, Kenneth S. Docherty ${ }^{3}$, Jose L. Jimenez ${ }^{4}$, \\ John H. Seinfeld ${ }^{5}$, and Anthony S. Wexler ${ }^{1}$ \\ ${ }^{1}$ Department of Civil and Environmental Engineering, University of California, Davis, CA, USA \\ ${ }^{2}$ Department of Mechanical Engineering, Colorado State University, Fort Collins, CO, USA \\ ${ }^{3}$ Alion Science and Technology, Research Triangle Park, NC, USA \\ ${ }^{4}$ Cooperative Institute for Research in Environmental Sciences and Department Chemistry and Biochemistry, \\ University of Colorado, Boulder, CO, USA \\ ${ }^{5}$ Division of Chemistry and Chemical Engineering and Division of Engineering and Applied Science, \\ California Institute of Technology, Pasadena, CA, USA
}

Correspondence to: Christopher D. Cappa (cdcappa@ucdavis.edu)

Received: 21 October 2015 - Published in Atmos. Chem. Phys. Discuss.: 3 November 2015

Revised: 29 January 2016 - Accepted: 19 February 2016 - Published: 9 March 2016

\begin{abstract}
The influence of losses of organic vapors to chamber walls during secondary organic aerosol (SOA) formation experiments has recently been established. Here, the influence of such losses on simulated ambient SOA concentrations and properties is assessed in the University of California at Davis / California Institute of Technology (UCD/CIT) regional air quality model using the statistical oxidation model (SOM) for SOA. The SOM was fit to laboratory chamber data both with and without accounting for vapor wall losses following the approach of Zhang et al. (2014). Two vapor wall-loss scenarios are considered when fitting of SOM to chamber data to determine best-fit SOM parameters, one with "low" and one with "high" vapor wall-loss rates to approximately account for the current range of uncertainty in this process. Simulations were run using these different parameterizations (scenarios) for both the southern California/South Coast Air Basin (SoCAB) and the eastern United States (US). Accounting for vapor wall losses leads to substantial increases in the simulated SOA concentrations from volatile organic compounds (VOCs) in both domains, by factors of $\sim 2-5$ for the low and $\sim 5-10$ for the high scenarios. The magnitude of the increase scales approximately inversely with the absolute SOA concentration of the no loss scenario. In SoCAB, the predicted SOA fraction of total or-
\end{abstract}

ganic aerosol (OA) increases from $\sim 0.2$ (no) to $\sim 0.5$ (low) and to $\sim 0.7$ (high), with the high vapor wall-loss simulations providing best general agreement with observations. In the eastern US, the SOA fraction is large in all cases but increases further when vapor wall losses are accounted for. The total OA / $\triangle \mathrm{CO}$ ratio captures the influence of dilution on SOA concentrations. The simulated OA / $\triangle \mathrm{CO}$ in SoCAB (specifically, at Riverside, CA) is found to increase substantially during the day only for the high vapor wall-loss scenario, which is consistent with observations and indicative of photochemical production of SOA. Simulated O : C atomic ratios for both SOA and for total OA increase when vapor wall losses are accounted for, while simulated $\mathrm{H}: \mathrm{C}$ atomic ratios decrease. The agreement between simulations and observations of both the absolute values and the diurnal profile of the $\mathrm{O}: \mathrm{C}$ and $\mathrm{H}: \mathrm{C}$ atomic ratios for total OA was greatly improved when vapor wall-losses were accounted for. These results overall demonstrate that vapor wall losses in chambers have the potential to exert a large influence on simulated ambient SOA concentrations, and further suggest that accounting for such effects in models can explain a number of different observations and model-measurement discrepancies. 


\section{Introduction}

Particulate organic matter, or organic aerosol (OA), is derived from primary emissions or from secondary chemical production in the atmosphere from the oxidation of volatile organic compounds (VOCs). OA makes up a substantial fraction of atmospheric submicron particulate matter (Zhang et al., 2007), influencing the atmospheric fate and impact of PM on regional and global scales. Gas-phase oxidation of VOCs leads to the formation of oxygenated product species that can condense onto existing particles or nucleate with other species to form new particles (e.g. Ziemann and Atkinson, 2012). Much of the understanding regarding the formation of secondary organic aerosol (SOA) via condensation has been derived from experiments conducted in laboratory chambers. In a typical experiment, a precursor VOC is added to the chamber and exposed to an oxidant (e.g $\mathrm{OH}, \mathrm{O}_{3}$ or $\mathrm{NO}_{3}$ ). As both the precursor VOC and the oxidation products react with the oxidant, SOA is formed. The amount of SOA formed per amount of precursor reacted (i.e. the SOA mass yield) can then be quantified (e.g. Odum et al., 1996). Such SOA yield measurements form the basis of most parameterizations of SOA formation in regional air quality and global chemical-transport and climate models (Tsigaridis et al., 2014). However, too often simulated SOA concentrations underestimate observed values, especially in polluted regions, and sometimes dramatically so (Heald et al., 2005; Volkamer et al., 2006; Ensberg et al., 2014). There have been various efforts to account for model-measurement disparities including, most notably, (i) the addition of new SOA precursors in the form of so-called semi-volatile and intermediate volatility organic compounds, S/IVOCs, including treating primary organic aerosol as semi-volatile (Robinson et al., 2007); (ii) the addition of ad hoc "ageing" schemes on top of existing parameterizations of SOA from VOCs (Lane et al., 2008b; Tsimpidi et al., 2010; Dzepina et al., 2011); (iii) updating of aromatic SOA yields (Dzepina et al., 2009); and (iv) production of SOA in the aqueous phase in aerosolwater, clouds and fogs (Ervens et al., 2011). More recently, concerns over the influence of vapor wall losses on the experimental chamber data used to develop the parameterizations have arisen (Matsunaga and Ziemann, 2010; Zhang et al., 2014). The influence of erroneously low SOA yields due to vapor wall losses on simulated SOA concentrations in threedimensional (3-D) regional models and properties is the focus of the current work.

Recent observations have demonstrated that organic vapors can be lost to Teflon chamber walls, and that the extent of loss is related to the compound vapor pressures with lower vapor pressure compounds partitioning more strongly to the walls than higher vapor pressure compounds (Matsunaga and Ziemann, 2010; Kokkola et al., 2014; Krechmer et al., 2015; Yeh and Ziemann, 2015; Zhang et al., 2015). These results suggest that vapor wall losses during SOA formation experiments could potentially bias observed SOA concentra- tions. Indeed, Zhang et al. (2014) observed that SOA yields from toluene $+\mathrm{OH}$ photooxidation depend explicitly on the seed particle surface area, all other conditions being equal. They interpreted these observations using a dynamic model of particle growth coupled with a parameterizable gas-phase chemical mechanism, the statistical oxidation model (SOM; Cappa and Wilson, 2012). They determined that substantial vapor wall losses were most likely the cause of this dependence, with biases of up to a factor of $\sim 4$ for these experiments. Further, they estimated for this system that the vapor wall-loss rate coefficient ( $k_{\text {wall }}$ ) was $\sim 2 \times 10^{-4} \mathrm{~s}^{-1}$ for their $25 \mathrm{~m}^{3}$ chamber. This value of $k_{\mathrm{wall}}$ is in reasonable agreement both with theoretical expectations - so long as the vapor-wall accommodation coefficient $\left(\alpha_{\text {wall }}\right)$ is $>10^{-5}$ - and with results of Ziemann and colleagues (Matsunaga and Ziemann, 2010; Yeh and Ziemann, 2015), who estimated $k_{\text {wall }}$ $\sim 6 \times 10^{-4} \mathrm{~s}^{-1}$ for their $8 \mathrm{~m}^{3}$ chamber. Kokkola et al. (2014) have also suggested vapor wall losses can impact SOA yields, although they determined a much larger $k_{\text {wall }}$ of $\sim 10^{-2} \mathrm{~s}^{-1}$ for their $4 \mathrm{~m}^{3}$ chamber. Recent direct measurements of $k_{\text {wall }}$ for a range of oxidized VOCs (OVOCs), produced from reactions of VOCs in traditional chambers, suggest that $k_{\text {wall }}$ can vary by an order of magnitude $\left(\sim 2 \times 10^{-6}-3 \times 10^{-5} \mathrm{~s}^{-1}\right)$ and that $k_{\text {wall }}$ is dependent on the OVOC vapor pressure (Zhang et al., 2015); such low $k_{\text {wall }}$ values imply that the $\alpha_{\text {wall }}$ is $<10^{-5}$ and controls the rate of vapor loss to the walls.

Although the exact value of $k_{\text {wall }}$ is likely chamber-specific (which likely contributes to some of the abovementioned variability in $k_{\text {wall }}$ ) and thus the exact influence of vapor wall losses on chamber SOA measurements remains somewhat uncertain, the preponderance of evidence suggests that such effects are important. Existing SOA parameterizations have typically not been determined with explicit accounting for vapor wall losses. Consequently, they likely underestimate actual SOA formation in the atmosphere where walls are much less important (although dry deposition of vapors may still be a factor; Hodzic et al., 2014). Two recent efforts have attempted to estimate the influence of vapor wall losses on SOA concentrations in the atmosphere (Baker et al., 2015; Hayes et al., 2015). One of the studies (Baker et al., 2015) builds on the existing two-product parameterization of SOA formation in the Community Multiscale Air Quality (CMAQ) model and simply scales the yields of the semi-volatile products up by factors of 4 . In the two-product model, a given VOC reacts to form two semi-volatile products that partition to the condensed phase. The semi-volatile products are formed with mass yields, $y_{i}$, and partitioning coefficients, $K_{i}$, that have been determined by fitting the model to data from chamber experiments in which vapor wall losses were not accounted for. The other study (Hayes et al., 2015) used a similar yield-scaling approach, but within the volatility basis set (VBS) four-product framework to represent SOA formation, and they scaled the mass yields for only the semivolatile product species from aromatics. Not surprisingly, these simple ad hoc scaling methods demonstrated that in- 
creasing the yields of the semi-volatile products from their originally parameterized values increases the simulated SOA concentration, but quantitative interpretation of the results is difficult. This is an especially important consideration given that different SOA systems may exhibit different sensitivities to vapor wall losses, owing to differences in the product species volatility distribution and the extent to which multigenerational ageing influences the SOA formation. More robust assessment of the influence of vapor wall losses on simulated SOA concentrations in regional air quality models is thus needed.

In this study, the SOM SOA model (Cappa and Wilson, 2012) is utilized to examine the influence of vapor wall losses on simulated SOA concentrations and $\mathrm{O}: \mathrm{C}$ atomic ratios in a 3-D regional air quality model, specifically the University of California at Davis / California Institute of Technology (UCD/CIT) (Kleeman and Cass, 2001). What distinguishes the present approach is that the potential influence of vapor wall losses is inherently accounted for during the development of the SOM SOA parameterization (Zhang et al., 2014). This can be contrasted with a simple scaling of an existing parameterization. The current approach allows for more detailed characterization of different precursor species, reaction conditions (e.g. $\mathrm{NO}_{x}$ sensitivities) and the complex interplay of various timescales (reaction, gas/wall partitioning and gas/particle partitioning). This also allows for examination of the extent to which different assumptions regarding the value of $k_{\text {wall }}$ (i.e. the first-order rate constant for vapor loss to chamber walls) during development of the SOA parameterization impact simulations of ambient SOA concentrations. Further, the SOM framework simulates $\mathrm{O}: \mathrm{C}$ atomic ratios in addition to OA mass concentrations, and thus allows for more detailed assessment of the simulated OA and comparison with observations. Our results demonstrate that accounting for vapor wall losses can have a substantial impact on simulated SOA concentrations and suggest that there may be regionally specific differences.

\section{Methods}

\subsection{Air quality model}

Regional air quality simulations were performed using the UCD/CIT chemical-transport model (Kleeman and Cass, 2001) for two geographical domains: (i) the Southern California Air Basin (SoCAB) and (ii) the eastern United States (US). Details regarding the general model configuration and emissions inventory used have been previously discussed (Jathar et al., 2015a), and the reader is referred to that work for further information. Details specific to the current work are provided in the following sections. Model simulations were run for SoCAB from 20 July to 2 August 2005 and for the eastern US from 20 August to 2 September 2006. Model spatial resolution was higher in $\mathrm{SoCAB}(8 \mathrm{~km} \times 8 \mathrm{~km})$ than in the eastern US $(36 \mathrm{~km} \times 36 \mathrm{~km})$ to account for the different domain sizes.

\subsection{Statistical oxidation model for SOA}

SOA formation from six VOC classes was simulated using the statistical oxidation model (Cappa and Wilson, 2012; Cappa et al., 2013), which was recently implemented in the UCD/CIT model (Jathar et al., 2015a). The VOC classes considered are long alkanes, benzene, high-yield aromatics (i.e. toluene), low-yield aromatics (i.e. m-xylene), isoprene and terpenes (including both mono- and sesquiterpenes). SOM is a parameterizable model that simulates the multigenerational oxidation of the product species formed from reaction of the SOA precursor VOCs. In SOM, a "species" is defined as a molecule with a specific number of carbon and oxygen atoms $\left(N_{\mathrm{C}}\right.$ and $N_{\mathrm{O}}$, respectively), and where the VOC-specific properties of these SOM species are determined through fitting to laboratory observations. Reactions of a SOM species lead to either functionalization (i.e. addition of oxygen atoms while conserving the number of carbon atoms) or fragmentation (i.e. the production of two species, which individually have fewer carbon atoms but where the total carbon is conserved, and where each new species adds one additional oxygen atom). The particular tunable parameters in SOM are the probability of adding one, two, three or four oxygen atoms per reaction, referred to as $p_{\mathrm{XO}}$; the decrease in vapor pressure per added oxygen, referred to as $\triangle \mathrm{LVP}$; and the probability of fragmentation, which is related to the $\mathrm{O}: \mathrm{C}$ atomic ratio of a given species as $P_{\text {frag }}=(\mathrm{O}: \mathrm{C})^{m_{\text {frag }}}$ and where $m_{\text {frag }}$ is the tunable parameter. SOA formation from the semi-volatile SOM species assumes that partitioning is described according to absorptive gas-particle partitioning theory (Pankow, 1994), and the gasparticle mass transfer has been simulated using dynamic partitioning (Kleeman and Cass, 2001; Zhang et al., 2014; Jathar et al., 2015a). The parameters used in the current work have been determined by fitting them to time-dependent data from SOA formation experiments conducted in the Caltech chamber both with and without accounting for vapor wall losses during the fitting process (discussed further below); references for the specific experiments considered are provided in Table S1 in the Supplement. The specific influence of considering multi-generational ageing on simulated SOA concentrations and properties is discussed in a companion paper (Jathar et al., 2016). The use of the SOM to represent SOA formation leads to an increase of about a factor of 2.5 or less in computer processing time required compared to use of the two-product model. 


\subsection{Accounting for vapor wall loss}

\subsubsection{SOM}

Vapor wall losses have been accounted for using SOM, as detailed in Zhang et al. (2014). Vapor wall loss is treated as a reversible, absorptive process with vapor uptake specified using a first-order rate coefficient $\left(k_{\text {wall }}\right)$ and the desorption rate related to the effective saturation concentration, $C^{*}$, of the organic species and the effective absorbing mass of the walls (Matsunaga and Ziemann, 2010). Unique SOM fits (i.e. values of $m_{\text {frag }}, \Delta \mathrm{LVP}$ and $p_{\mathrm{XO}}$ ) have been determined for different assumed values of $k_{\text {wall }}$. Best-fit values are provided in Table S1. It should be noted that the influence of vapor wall losses is inherent in the fit parameters, and in the absence of walls (i.e. in the atmosphere) the predicted SOA formed will be larger when the fits account for vapor wall losses. A base case set of parameters with no vapor wall losses assumed during fitting (termed SOM-no) was determined using $k_{\text {wall }}=0$. In Zhang et al. (2014), an optimal value of $k_{\mathrm{wall}}=2 \times 10^{-4} \mathrm{~s}^{-1}$ was determined for the California Institute of Technology chamber based on simultaneous fitting of the SOM to a set of toluene photooxidation experiments conducted at different seed particle concentrations. Unlike in Zhang et al. (2014), the values of $k_{\text {wall }}$ used here were not determined during model fitting. This is because the absolute value of $k_{\text {wall }}$ is not well constrained by a single experiment, and the simulations require vapor wallloss-corrected parameters for VOCs besides toluene. Therefore, two specific bounding cases that account for vapor wall loss are instead considered based on the results from Zhang et al. (2014). Specifically, values of $k_{\mathrm{wall}}=1 \times 10^{-4}$ and $2.5 \times 10^{-4} \mathrm{~s}^{-1}$ are considered, corresponding to a low vapor wall-loss case (SOM-low) and high vapor wall-loss case (SOM-high), respectively.

An important aspect of vapor wall loss is that the impact it has on SOA concentrations is dependent upon the timescale associated with vapor-particle equilibration $\left(\tau_{\mathrm{v}-\mathrm{p}}\right.$; McVay et al., 2014; Zhang et al., 2014). The $\tau_{\mathrm{v}-\mathrm{p}}$ is related to the accommodation coefficient associated with vapor condensation on particles, $\alpha_{\text {particle }}$. Above a vapor-particle accommodation coefficient of $\alpha_{\text {particle }} \sim 0.1$ variations in the exact value of $\alpha_{\text {particle }}$ does not influence the effects of vapor wall losses. This is not to say that vapor wall losses have no influence on the amount of SOA formed when $\alpha_{\text {particle }} \geq 0.1$, only that the net impact does not depend on $\alpha_{\text {particle }}$. Below this value, vapor-particle equilibration is slowed and the effects of loss of vapors to the walls are accentuated. Thus, a conservative estimate that minimizes the influence of vapor wall losses on SOA formation is obtained using $\alpha_{\text {particle }} \geq 0.1$. Here, data fitting and parameter determination was performed assuming that $\alpha_{\text {particle }}=1$, and is thus a conservative estimate.

SOM was fit to time-dependent SOA formation experiments conducted in the California Institute of Technology chamber, following the methodologies described in Cappa et al. (2013) and Zhang et al. (2014). Observed suspended particle concentrations have been corrected only for physical deposition on chamber walls, which is appropriate since vapor wall losses are accounted for separately by SOM. Bestfit values for the SOM parameters for the base case (SOMno) are given in Jathar et al. (2015a) and values for SOMlow and SOM-high determined here are given in Table S1, along with the sources of the experimental data. Parameters have been separately determined for experiments conducted under low- $\mathrm{NO}_{x}$ and high- $\mathrm{NO}_{x}$ conditions since the SOA yields differ. Example results that illustrate the influence of vapor wall losses on simulated SOA yields are presented in Fig. S1 in the Supplement for box model simulations that have been conducted using the best-fit parameters determined for toluene SOA (low- $\mathrm{NO}_{x}$ conditions), but where the simulations are run assuming there are no walls (i.e. by setting $k_{\text {wall }}=0$ ).

\subsubsection{Two-product model}

Ideally, SOA levels from the SOM-based simulations can be compared with similar results based on the commonly used two-product model. To do so involves determining new parameters for the two-product model in which vapor wall losses are explicitly accounted for. Therefore, vapor wallloss-corrected SOA yield curves (i.e. [SOA] vs. [ $\Delta \mathrm{HC}]$, where $\triangle \mathrm{HC}$ is the concentration of reacted hydrocarbon) were generated with SOM using the parameters determined by fitting SOM to the original chamber data when $k_{\text {wall }}>0$, but now where $k_{\text {wall }}$ is set to zero. The two-product model could then be fit to these "corrected" yield curves to determine vapor wall-loss-corrected yields and partitioning coefficients. These new fits would inherently account for the influence of vapor wall loss since the two-product model is being fit to the corrected "wall-less" data and thus differ from ad hoc scaling of yields. However, it was determined that the two-product fits were not sufficiently robust across the entire suite of compounds and vapor wall-loss conditions considered to be implemented in the atmospheric model. An example for SOA from dodecane $+\mathrm{OH}$ under low- $\mathrm{NO}_{x}$ reaction conditions is shown in Fig. S2. We have determined that this lack of robustness is a result of the limited dynamic range of the two-product model. This can be contrasted with the SOM, which includes many more species that span a wider, more continuous volatility range, making it more flexible when fitting the laboratory data. More specifically, the SOA concentrations from the chamber observations, both uncorrected and corrected, ranged from $\sim 1$ to $500 \mu \mathrm{g} \mathrm{m}^{-3}$, often with few data points at concentrations less than $\sim 10 \mu \mathrm{g} \mathrm{m}^{-3}$. Thus, when fits were performed, inconsistent behavior between the different vapor wall-loss conditions was obtained over the atmospherically relevant concentration range $\left(\sim 0.1-20 \mu \mathrm{g} \mathrm{m}^{-3}\right)$. Attempts were made to fit the two-product model over a restricted concentration range or to fit using $\log ([\mathrm{SOA}])$ instead of [SOA]. However, neither 
effort led to sufficiently robust results (although both did lead to improvements). This null result suggests that simple scaling of two-product yields (Baker et al., 2015) to account for the effects of vapor wall losses may not be appropriate. This may similarly apply to scaling of VBS parameters (Hayes et al., 2015), although the greater flexibility of the VBS (commonly implemented with four products, instead of two) can potentially allow for unique "wall-less" fits to be determined (Hodzic et al., 2015). The extent to which such alternative methods can robustly account for vapor wall losses that are computationally less intensive than SOM will be explored in future work.

\subsection{Primary organic aerosol and IVOCs}

Primary organic aerosol (POA) derived from anthropogenic (e.g. vehicular activities, food cooking) or pyrogenic (e.g. wood combustion) sources are simulated assuming that the POA is non-volatile. This is the standard assumption in the CMAQ model framework (Simon and Bhave, 2011), and thus is adopted here. It is known that some POA is semivolatile, not non-volatile as assumed here. Had POA been treated within a semi-volatile framework (Robinson et al., 2007), such that some fraction of the POA can evaporate (i.e. SVOCs) and react within the gas-phase and be converted to SOA (sometimes improperly referred to as "oxidized POA"), then the amount of POA would likely decrease (due to evaporation) and the amount of simulated SOA would increase (due to condensation of oxidized SVOC vapors); the total $\mathrm{OA}$ concentration (POA + SOA) may or may not increase as a result, depending on the details of the parameterization and the atmospheric conditions. Additionally, nearly all modeling efforts in which POA is treated as semi-volatile have also included contributions from gas-phase IVOCs as an added class of SOA precursors; these two issues are rarely implemented independently in models, although their contributions can be separately tracked. Whereas simply treating POA as semi-volatile may or may not lead to an increase in the total OA concentration, the introduction of new SOA precursor mass in the form of IVOCs will inevitably lead to production of more SOA in the model. The relative importance of IVOCs will depend on the amount of added IVOC mass and the propensity of these IVOC vapors to form SOA in the model (i.e. their effective SOA yield). In the current study, we do not explicitly consider the potential for IVOCs to contribute to the ambient SOA burden, focusing instead on how vapor wall losses influence SOA formation from VOCs. We will aim to consider contributions from IVOCs and how they are influenced by vapor wall losses in future studies. Regardless, the implications of our particular treatment (non-volatile POA excluding IVOCs) are discussed below.

\subsection{Model simulations and outputs}

Six individual model simulations have been carried out to determine the spatial distribution of SOA concentrations. Each simulation used one of the SOM parameterizations, i.e. SOM-no, SOM-low or SOM-high with either the lowor high- $\mathrm{NO}_{x}$ parameters. Each precursor VOC is allowed to react with either $\mathrm{OH}, \mathrm{O}_{3}$ or $\mathrm{NO}_{3}$ as characterized by an oxidant-specific rate coefficient, although the products and product distributions of the first-generation products are assumed to be oxidant independent. This simplification is identical to that employed in CMAQv4.7 (Carlton et al., 2010). Reactions of subsequent oxidized SOM products then occur only via reaction with $\mathrm{OH}$ radicals according to the SOM parameterization associated with that precursor VOC (as determined by fitting the photooxidation experiments). Besides the absolute SOA concentration, SOM also allows for explicit calculation of the average (and precursor-specific) $\mathrm{O}: \mathrm{C}$ and $\mathrm{H}: \mathrm{C}$ atomic ratios and of the SOA volatility distribution, which characterizes the distribution of particulate and gasphase mass concentrations with respect to $C^{*}$. To estimate the $\mathrm{O}: \mathrm{C}$ of the total OA $(\mathrm{POA}+\mathrm{SOA})$, it is assumed that the non-volatile POA has a constant $\mathrm{O}: \mathrm{C}=0.2$ and $\mathrm{H}: \mathrm{C}=2.0$ ( $\mathrm{Ng}$ et al., 2011). Since the simulated $(\mathrm{O}: \mathrm{C})_{\text {total }}$ is just a combination of $(\mathrm{O}: \mathrm{C})_{\text {SOA }}$ and $(\mathrm{O}: \mathrm{C})_{\mathrm{POA}}$, assuming a different value for $(\mathrm{O}: \mathrm{C})_{\mathrm{POA}}$ would change the absolute value of $(\mathrm{O}: \mathrm{C})_{\text {total }}$ but not any dependence on simulation conditions. This is similarly true for $(\mathrm{H}: \mathrm{C})_{\text {total }}$.

As noted above, unique sets of SOM parameters were fit to experiments conducted under either low- or high-NO $\mathrm{N}_{x}$ conditions assuming a particular value for $k_{\text {wall }}$. Since each simulation used a single set of SOM fit parameters (e.g. SOM-no fit to low- $\mathrm{NO}_{x}$ experiments), the $\mathrm{SOA} \mathrm{NO} x$ parameterization used in a given simulation is independent of the actual simulated ambient $\mathrm{NO}_{x}$ concentrations or $\mathrm{NO} / \mathrm{HO}_{2}$ ratio. Consequently, comparison between the simulations conducted using the low- and high- $\mathrm{NO}_{x}$ parameterizations gives an indication of the range expected from variability in $\mathrm{NO}_{x}$ levels, and the average between the two simulations provides a representation that is intermediate between these two extremes. Unless otherwise specified, reported values are for the average of the simulations run using the low- and high- $\mathrm{NO}_{x}$ parameterizations. This approach towards understanding the influence of $\mathrm{NO}_{x}$ is different than some previous approaches that attempted to account for the $\mathrm{SOA} \mathrm{NO}_{x}$ dependence in a more continuously variable manner. For example, some simulations using the two-product approach have used the instantaneous $\mathrm{NO} / \mathrm{HO}_{2}$ ratios predicted by the model to allow for distinguishing between low- and high- $\mathrm{NO}_{x}$ products and SOA yields for aromatic VOCs (Carlton et al., 2010). Similarly, instantaneous $\mathrm{VOC} / \mathrm{NO}_{x}$ ratios have been used with VBS-type models for aromatic VOCs to allow for interpolation between the two regimes (Lane et al., 2008a). Typically, these efforts have not considered the $\mathrm{NO}_{x}$ dependence of monoterpene and sesquiterpene yields even though 


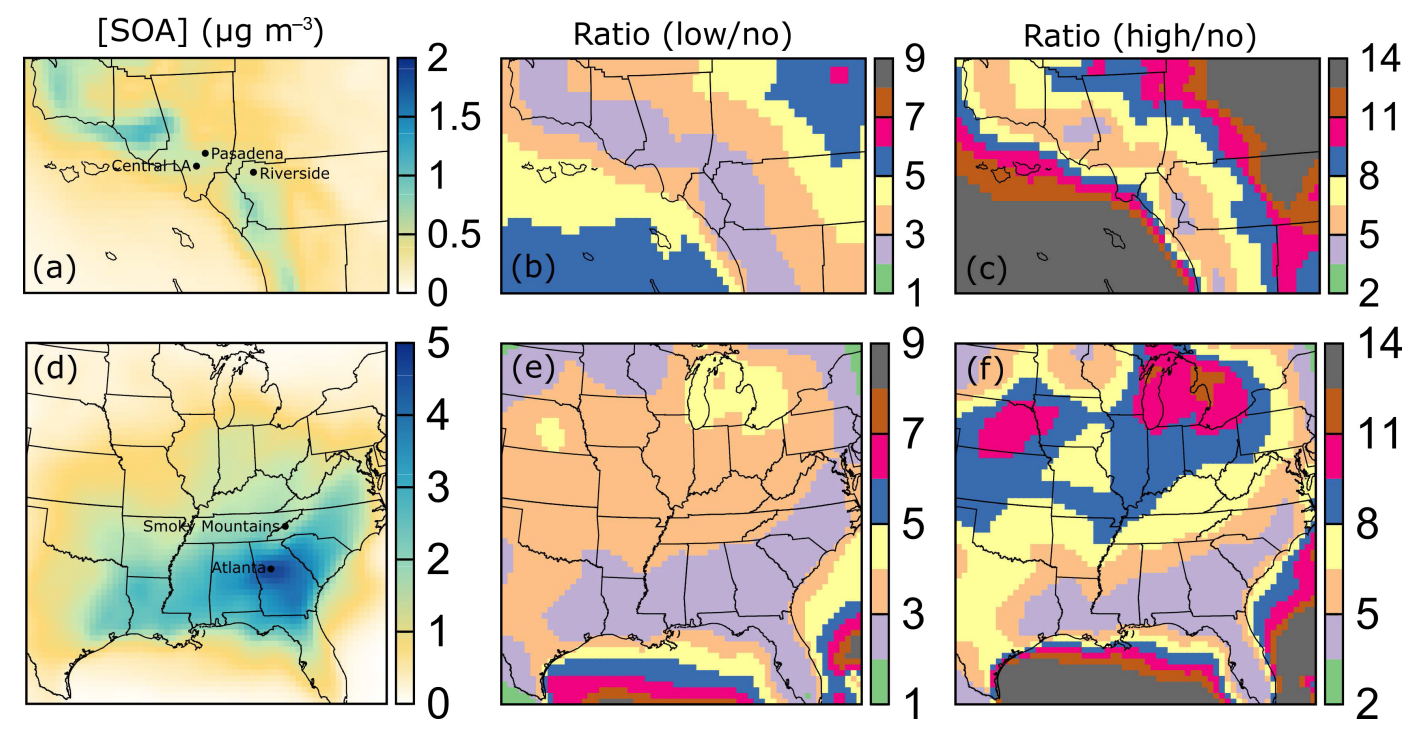

Figure 1. 14-day averaged SOA concentrations, in $\mu \mathrm{g} \mathrm{m}^{-3}$, for (a) SoCAB and (d) the eastern US for the SOM-no simulations. The averaging time periods are from 20 July to 2 August 2005 for SoCAB and from 20 August to 2 September 2006 for the eastern US. Panels (b, e) show the ratio between the SOA concentrations for the SOM-low and the SOM-no simulations and panels (c, f) show the ratio between the SOMhigh and SOM-no simulations. Results shown in all panels are the average of the low- and high- $\mathrm{NO}_{x}$ simulations. Note that the color scale for the absolute SOA concentration is continuous whereas the color scale in the ratio plots is discrete.

it is experimentally established that the $\mathrm{NO}_{x}$ condition (and more specifically, the $\mathrm{NO} / \mathrm{HO}_{2}$ ratio) influences SOA yields for both aromatic and biogenic compounds (e.g. $\mathrm{Ng}$ et al., 2007a, b). For most VOCs, the functional dependence of the SOA yield on the $\mathrm{VOC} / \mathrm{NO}_{x}$ ratio or the $\mathrm{NO} / \mathrm{HO}_{2}$ ratio is not well established, making it difficult to understand how well the interpolation methods work (SOA formation from isoprene is a notable exception; e.g. Xu et al., 2014). Further, modeled $\mathrm{NO} / \mathrm{HO}_{2}$ ratios may be off by orders of magnitude, most likely due to poor representation of $\mathrm{HO}_{2}$ concentrations (Carlton et al., 2010), making it difficult to understand how well the conditions of the laboratory translate to the model environment. By considering the low- and high- $\mathrm{NO}_{x}$ parameterizations separately, i.e. the approach used in the current study, bounds on the overall influence of $\mathrm{NO}_{x}$ on the simulated SOA can be established. However, this approach will not capture how the simulated SOA may vary due to spatial and temporal variations in the model $\mathrm{NO}_{x}$ and oxidant fields. Future efforts will aim to account for the $\mathrm{NO}_{x}$ dependence of SOA formation in a more continuously varying manner, and to account for recent updates to the detailed isoprene oxidation mechanism (Pye et al., 2013).

\section{Results and discussion}

\subsection{General influence of vapor wall loss on simulated SOA}

The spatial distribution of the SOM-no model SOA concentrations is shown for SoCAB and the eastern US us- ing the average from the simulations carried out using the low- and high- $\mathrm{NO}_{x}$ parameterizations (Fig. 1a-b; again, the low- and high- $\mathrm{NO}_{x}$ designations here refer only to the experimental conditions under which the SOM parameters were determined, not the actual $\mathrm{NO}_{x}$ conditions in the UCD/CIT model). For SoCAB, predicted SOA concentrations are largest in and around downtown Los Angeles and in the forested regions of the Los Padres National Forest and the Santa Monica Mountains National Recreation Area in the northwest (NW) quadrant. The spatial distribution of SOA is similar to that obtained using the conventional twoproduct SOA parameterization (Jathar et al., 2015a, b). For the eastern US, predicted SOA concentrations are largest in the southeast, in particular around Atlanta, Georgia. Overall, the simulated SOA concentrations with the SOM-no model are larger in the eastern US than in SoCAB, reflecting the relatively strong influence of biogenic emissions in this region.

The influence of vapor wall losses on the simulated ambient SOA concentrations is illustrated in Fig. 1c-f as the ratio between the SOA from the SOM-low and SOM-high simulations to the SOM-no (no wall losses) simulation. This ratio will be referred to generally as the wall loss impact $\left(R_{\text {wall,low }}\right.$ or $R_{\text {wall,high }}$ ). Values of $R_{\text {wall }}$ larger than 1 indicate that accounting for vapor wall losses as part of the SOM parameterization leads to an increase in the predicted SOA concentrations. In the SoCAB, the $R_{\text {wall,low }}$ varies from 1.5 to 4.5 ,

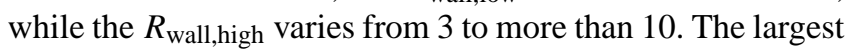
ratios (indicating the largest impact of accounting for vapor wall losses) tend to occur in more remote locations as this 
is where concentrations are lower (Fig. 2). However, the impact is still large in downtown Los Angeles and the greater LA region (average $R_{\text {wall,low }} \sim 2.5$ and $R_{\text {wall, high }} \sim 5$ ). In the eastern US, the simulated $R_{\text {wall }}$ vary over a similar range as

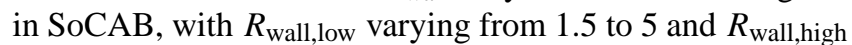
from 3 to 10 . There is again a general, although not exact, inverse relationship between $R_{\text {wall }}$ and the absolute SOA concentrations; the greater scatter in the eastern US compared to SoCAB at low SOA concentrations likely reflects the larger spatial range considered. The smallest simulated $R_{\text {wall }}$ values occur across the southeast and up the eastern seaboard ( $R_{\text {wall,low }} \sim 2.5$ and $R_{\text {wall,high }} \sim 5$ ) while the largest values occur over the Great Lakes and Michigan, Nebraska, and the Gulf of Mexico and Atlantic Ocean; there is a steep increase going from land to sea. If $R_{\text {wall }}$ values are calculated using the simulated SOA concentrations from either the low- $\mathrm{NO}_{x}$ or high- $\mathrm{NO}_{x}$ parameterizations individually, as opposed to the average values used above, very similar results are obtained (Fig. S3).

Regional air quality models have historically overestimated the urban-to-regional gradient in total OA concentrations. Robinson et al. (2007) showed that the simulated urban-to-regional gradient could be reduced and made more consistent with observations by treating POA as semivolatile and adding SVOCs and IVOCs as SOA-forming species. The current results suggest a complementary explanation, namely that the urban-to-regional gradient, can be reduced when vapor wall losses are accounted for since $R_{\text {wall }}$ generally increases with decreasing SOA concentration and since POA is identical between the different model parameterizations. Consequently, larger $R_{\text {wall }}$ are found outside of the major source regions, which decreases the urban-toregional contrast. Indeed, the ratio between the predicted average SOA in downtown LA (urban) to that over the Pacific Ocean near the coast of LA (regional) and decreases from 2.3 (SOM-no) to 1.5 (SOM-low) to 1.3 (SOM-high), for example. Additionally, it has been suggested that the typical underprediction of SOA by air quality and chemical transport models relative to observations might increase with photochemical age (Volkamer et al., 2006). The current results suggest the possibility that the SOA concentrations in more remote (lower concentration) regions may be underestimated in models to a greater extent in a relative sense than in highsource (higher concentration) regions due to a lack of accounting for vapor wall losses, although the absolute differences in SOA concentrations may be larger in regions where absolute concentrations are larger.

\subsection{OA composition and concentrations}

The simulated fraction of total OA that is SOA $\left(f_{\mathrm{SOA}}\right)$ is substantially smaller in SoCAB than in the eastern US, especially the southeast US (Fig. 3 ). The predicted $f_{\text {SOA }}$ values vary spatially within a given region, with the SOM-no simulations in the general range of $\sim 0.1-0.3$ for SoCAB
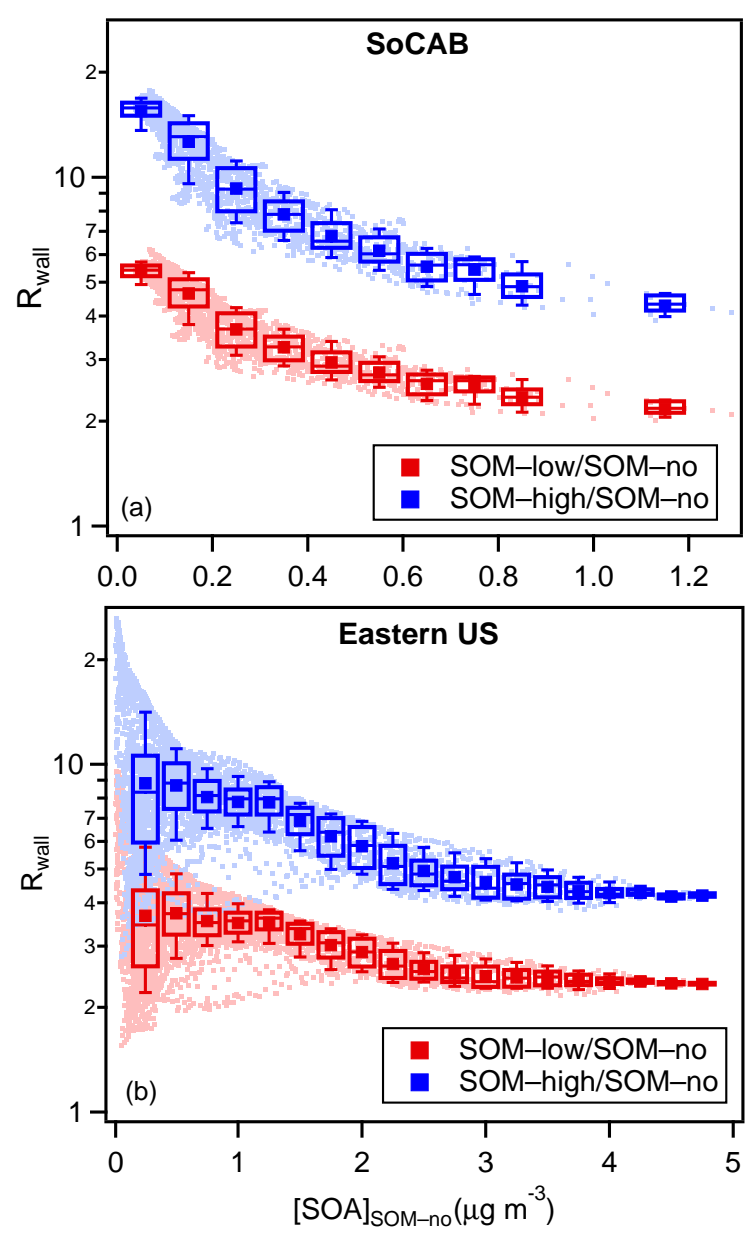

Figure 2. Variation of the ratio between simulated SOA concentrations from SOM-low (red) and SOM-high (blue) simulations to SOM-no simulations for (a) SoCAB and (b) the eastern US as a function of the absolute SOA concentration from the SOM-no simulations. Results shown are the average of the low- and high- $\mathrm{NO}_{x}$ simulations. Individual data points are shown along with box and whisker plots.

and $\sim 0.4-0.9$ for the eastern US. This difference between regions results from the substantial POA emissions in So$\mathrm{CAB}$ and the large emissions of biogenic VOCs across the southeast US. Consequently, accounting for vapor wall losses has a larger impact on the absolute total OA (SOA + POA) concentrations in the eastern US than it does in SoCAB, although the impact in both regions is substantial. For SoCAB, the predicted $24 \mathrm{~h}$ average $f_{\mathrm{SOA}}$ range increases to $\sim 0.2-0.5$ for SOM-low and to $\sim 0.4-0.8$ for SOM-high simulations. These model results can be compared with measurements from the 2005 SOAR field study in Riverside, CA, which overlaps with the simulation period. The observed $f_{\mathrm{SOA}}$ during SOAR ranged from $\sim 0.6$ in early morning to $\sim 0.9$ in midday, with a campaign-average of $\sim 0.78$ (Docherty et al., 2011). Measurements at Pasadena, CA, during a later time period, June 2010 during the CalNex study, give similar re- 
sults with the campaign-average $f_{\mathrm{SOA}}=0.6$ (Hayes et al., 2013). (Note that here we are equating SOA with the "oxygenated organic aerosol," or OOA factors that are obtained from positive matrix factorization of the measured OA time series, and equating POA with the sum of hydrocarbon-like OA (HOA), cooking-derived OA (COA), and "local" OA (LOA).) The SOM-high simulations in SoCAB are most consistent with these observations.

For the eastern US, the predicted $f_{\mathrm{SOA}}$ range increases from $0.4-0.9$ for SOM-no to $\sim 0.7-0.9$ for SOM-low and to $\sim 0.8-1$ for SOM-high. These predicted values can be compared with measurements made at a few locations in the southeastern US (specifically, sites in Alabama and Georgia), which show that the $f_{\mathrm{SOA}}$ in this region exhibits a strong seasonal dependence and some spatial variation (Xu et al., 2015b). The measurements in spring and summer indicate that the total OA is dominated by SOA, with $f_{\mathrm{SOA}}$ measurements ranging from 0.7 to 1 and with the smaller values observed at the more urban sites. The predicted $f_{\mathrm{SOA}}$ from the SOM-low and SOM-high simulations are most consistent with this range, with the $f_{\mathrm{SOA}}$ from the SOM-no simulations being on the low side, especially in comparison with the more rural sites.

The simulated total OA concentrations are compared to ambient OA measurements made at the STN (Speciated Trends Network) and IMPROVE (Interagency Monitoring of Protected Visual Environments; The Visibility Information Exchange Web System (VIEWS 2.0), 2015) air quality monitoring sites in SoCAB and the eastern US; the regional differences in $f_{\mathrm{SOA}}$ should be kept in mind for this modelmeasurement comparison. A map of sites is shown in Fig. S4. STN sites tend to be more urban and have higher OA concentrations compared to IMPROVE sites, which tend to be more remote. OA concentrations are estimated as the measured organic carbon (OC) concentrations times 2.1 for IMPROVE sites and as $1.6 \times\left([\mathrm{OC}]-0.5 \mu \mathrm{g} \mathrm{m}^{-3}\right)$ for STN sites (Turpin and Lim, 2001). The $-0.5 \mu \mathrm{g} \mathrm{m}^{-3}$ offset for the STN sites arises because the IMPROVE data are both artifact and blank corrected while the STN data are only artifact corrected (Subramanian et al., 2004). The difference in scaling factors (2.1 vs. 1.6) approximately accounts for differences in the OA/OC conversion between more urban and more rural networks (Turpin and Lim, 2001). Given the generally regional character of OA in much of the eastern US, it may be that the difference in OM/OC (the organic matter to organic carbon ratio) between the STN and IMPROVE sites may be smaller than assumed here (most likely with the 1.6 being too low, leading potentially to an underestimate in the OA at the STN sites). We note that IMPROVE data may also be biased low by $\sim 25 \%$ in the southeast (SE) US summer due to evaporation after sampling (Kim et al., 2015).

Table 1 lists statistical metrics of fractional bias, normalized mean square error (NMSE) and the concordance correlation coefficients that capture model performance for OA for all simulations for both domains across the STN and IM-
PROVE monitoring networks. Fractional bias is calculated as:

Fractional bias $=\frac{2\left(C_{\mathrm{OA}, \mathrm{sim}}-C_{\mathrm{OA}, \mathrm{obs}}\right)}{C_{\mathrm{OA}, \mathrm{sim}}+C_{\mathrm{OA}, \mathrm{obs}}}$

and the NMSE as

$\mathrm{NMSE}=\left|\frac{\left(C_{\mathrm{OA}, \mathrm{sim}}-C_{\mathrm{OA}, \mathrm{obs}}\right)^{2}}{C_{\mathrm{OA}, \mathrm{sim}} \times C_{\mathrm{OA}, \mathrm{obs}}}\right|$,

where the subscripts sim and obs refer to the simulated and observed OA concentrations, respectively. The concordance correlation coefficients $\left(\rho_{\mathrm{c}}\right)$ are calculated as

$\rho_{\mathrm{c}}=\frac{2 s_{\mathrm{sim}, \mathrm{obs}}}{s_{\mathrm{sim}}^{2}+s_{\mathrm{obs}}^{2}+\left(\overline{C_{\mathrm{OA}, \mathrm{sim}}}-\overline{C_{\mathrm{OA}, \mathrm{obs}}}\right)^{2}}$,

where $\overline{C_{\mathrm{OA}, \text { sim }}}$ and $\overline{C_{\mathrm{OA}, \text { obs }}}$ indicate the mean, $s_{\mathrm{sim}}^{2}$ and $s_{\mathrm{obs}}^{2}$ are the variance and $s_{\mathrm{sim}, \mathrm{obs}}$ is the covariance of the simulated and observed OA concentrations. Scatter plots are shown in Figs. S5 and S6; many more sites are considered in the eastern US than in the SoCAB given the larger geographical domain and distribution of sites. In both regions, the SOM-no simulations underpredict the STN and IMPROVE observations, especially in the SoCAB. The negative bias of the SOM-no simulations is generally improved as vapor wall losses are accounted for. For both the STN and IMPROVE sites in the SoCAB the SOM-high simulations give best agreement. For the eastern US STN sites, an average of the SOM-low and SOM-high simulations provides the best agreement. For the eastern US IMPROVE sites, the SOM-low simulations provide the best agreement, although with some overprediction. (If the eastern US STN and IMPROVE measurements do underestimate the actual OA concentrations, the degree to which accounting for vapor wall losses improves the model-measurement comparison will increase.) The simulated anthropogenic-biogenic SOA split is found to be approximately the same at sites within both networks (e.g. Fig. 4). This occurs even though the IMPROVE sites tend to be more remote than the STN sites in the eastern US, and reflects the regional character of SOA in that region. Ultimately, the comparisons suggest that accounting for vapor wall losses can improve model-measurement agreement, although there are differences in terms of whether the SOMhigh simulations or SOM-low simulations produce the best agreement. That the OA concentrations for the SOM-high simulations remains slightly lower than the observations for STN sites in SoCAB could potentially result from the nonvolatile treatment of POA, the exclusion of IVOCs in the current model or uncertainty in the POA emission inventory.

The simulations can also be compared with observations of the OA-to- $\Delta \mathrm{CO}$ concentration ratio $(\mathrm{OA} / \Delta \mathrm{CO})$ during the Study of Organic Aerosols at Riverside (SOAR) campaign (Docherty et al., 2008, 2011), and where $\Delta C O$ indicates the background-corrected $\mathrm{CO}$ concentration. Because 

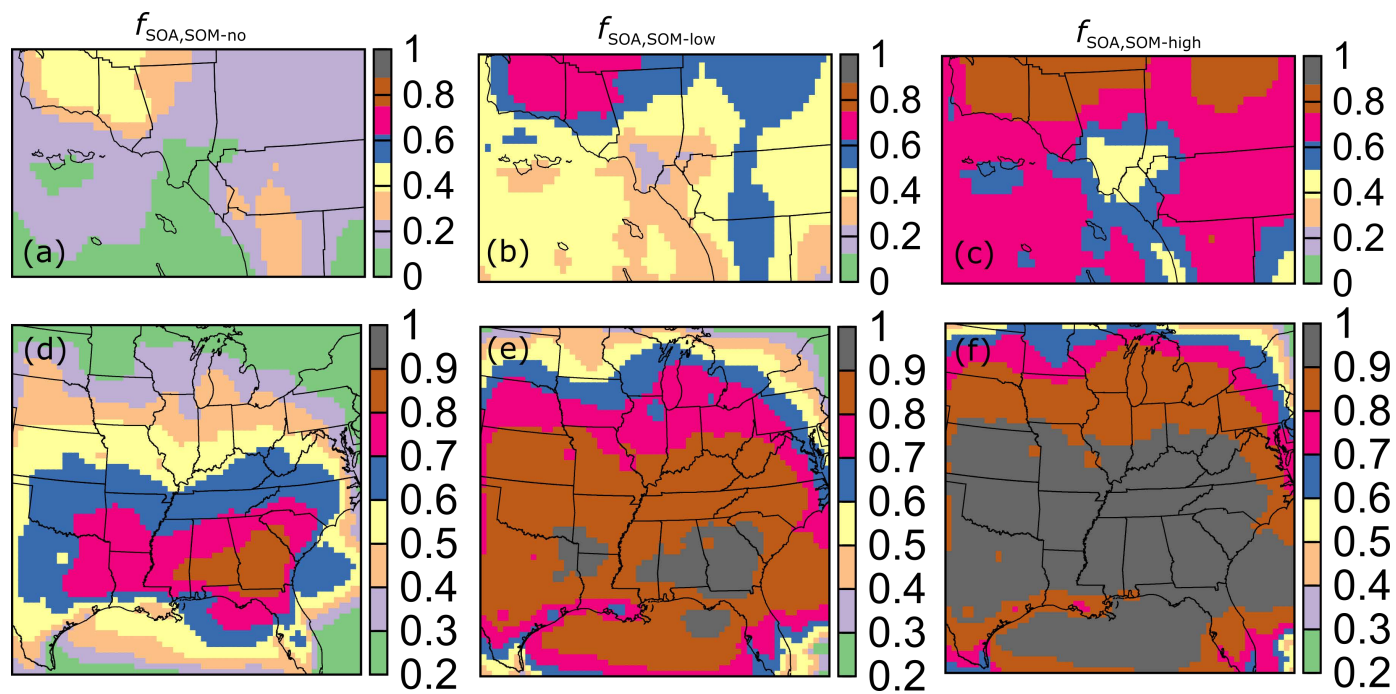

Figure 3. 14-day averaged $f_{\mathrm{SOA}}$, the ratio between SOA and total OA concentrations, for (top panels, a, b, c) SoCAB and (bottom panels, $\mathbf{d}, \mathbf{e}, \mathbf{f})$ the eastern US for the (a, d) SOM-no, (b, e) SOM-low and (c, f) SOM-high simulations.

Table 1. Model performance metrics determined for the three simulation groupings (SOM-no, SOM-low and SOM-high) for the low-NO , high- $\mathrm{NO}_{x}$ and average parameterizations for STN and IMPROVE sites in SoCAB and the eastern US. Fractional bias is calculated as 2 $\left(C_{\mathrm{OA}, \mathrm{sim}}-C_{\mathrm{OA}, \mathrm{obs}}\right) /\left(C_{\mathrm{OA}, \mathrm{sim}}+C_{\mathrm{OA}, \mathrm{obs}}\right)$ and NMSE as abs $\left[\left(C_{\mathrm{OA}, \mathrm{sim}}-C_{\mathrm{OA}, \mathrm{obs}}\right)^{2} /\left(C_{\mathrm{OA}, \text { sim }} \times C_{\mathrm{OA}, \text { obs }}\right)\right]$, and the reported values are the averages over all data points as percentages. Note that a negative fractional bias indicates observed [SOA] $>$ simulated [SOA], i.e. that the simulations are underpredicting. $\rho_{\mathrm{c}}$ are the concordance correlation coefficients from Eq. (3).

\begin{tabular}{|c|c|c|c|c|c|c|c|c|c|c|c|c|c|}
\hline \multirow[b]{3}{*}{ Simulation } & \multirow[b]{3}{*}{$\begin{array}{l}\mathrm{NO}_{x} \\
\text { parameterization }\end{array}$} & \multicolumn{6}{|c|}{ Southern California } & \multicolumn{6}{|c|}{ Eastern US } \\
\hline & & \multicolumn{3}{|c|}{$\mathrm{STN}^{\mathrm{a}}$} & \multicolumn{3}{|c|}{ IMPROVE $^{\mathrm{b}}$} & \multicolumn{3}{|c|}{$\operatorname{STN}^{\mathrm{a}}$} & \multicolumn{3}{|c|}{ IMPROVE ${ }^{\mathrm{b}, \mathrm{c}}$} \\
\hline & & $\begin{array}{l}\text { Frac. } \\
\text { Bias }\end{array}$ & NMSE & $\rho_{\mathrm{c}}$ & $\begin{array}{l}\text { Frac. } \\
\text { Bias }\end{array}$ & NMSE & $\rho_{\mathrm{c}}$ & $\begin{array}{l}\text { Frac. } \\
\text { Bias }\end{array}$ & NMSE & $\rho_{\mathrm{c}}$ & $\begin{array}{r}\text { Frac. } \\
\text { Bias }\end{array}$ & NMSE & $\rho_{\mathrm{c}}$ \\
\hline \multirow{4}{*}{ SOM-no } & low & -70 & 88 & 0.03 & -75 & 114 & 0.36 & -81 & 206 & 0.04 & -55 & 105 & 0.31 \\
\hline & high & -61 & 69 & 0.02 & -60 & 85 & 0.41 & -58 & 166 & 0.12 & -24 & 84 & 0.48 \\
\hline & average & -65 & 78 & 0.02 & -67 & 97 & 0.39 & -68 & 180 & 0.08 & -38 & 89 & 0.43 \\
\hline & low & -52 & 64 & -0.21 & -45 & 65 & 0.36 & -26 & 154 & 0.08 & 15 & 85 & 0.15 \\
\hline \multirow{3}{*}{ SOM-low } & high & -39 & 49 & -0.29 & -27 & 47 & 0.27 & -4 & 171 & 0.07 & 38 & 128 & 0.10 \\
\hline & average & -45 & 55 & -0.25 & -36 & 54 & 0.32 & -14 & 160 & 0.08 & 28 & 105 & 0.12 \\
\hline & low & -25 & 51 & -0.03 & -8 & 46 & 0.44 & 26 & 236 & 0.15 & 69 & 189 & 0.40 \\
\hline \multirow[t]{2}{*}{ SOM-high } & high & -10 & 38 & -0.08 & 16 & 43 & 0.46 & 45 & 298 & 0.15 & 86 & 295 & 0.25 \\
\hline & average & -17 & 43 & -0.05 & 5 & 42 & 0.46 & 36 & 265 & 0.16 & 79 & 241 & 0.31 \\
\hline
\end{tabular}

${ }^{\mathrm{a}}$ Observed $[\mathrm{OA}]$ for STN sites estimated as $1.6\left([\mathrm{OC}]-0.5 \mu \mathrm{g} \mathrm{m}{ }^{-3}\right) .{ }^{\mathrm{b}}$ Observed [OA] for IMPROVE sites estimated as 2.1 [OC]. ${ }^{\mathrm{c}}$ Observed [OA] may be biased low by $\sim 25 \%$ in the SE US summer due to evaporation after sampling (Kim et al., 2015).

$\mathrm{CO}$ is relatively long-lived, normalization of the calculated and observed OA to the concurrent background-corrected CO helps to minimize the impacts of uncertainties in boundary layer dynamics and accounts for variability in emissions and transport to some extent (De Gouw and Jimenez, 2009). The background-corrected $\mathrm{CO}$ concentration is calculated as $\Delta[\mathrm{CO}]=[\mathrm{CO}]-[\mathrm{CO}]_{\text {bgd }}$. The estimated $[\mathrm{CO}]_{\text {bgd }}$ for the observations is $105 \mathrm{ppb}$ (with a plausible range from 85 to $125 \mathrm{ppb}$; Hayes et al., 2013). In contrast, the [CO $]_{\text {bgd }}$ for the model is estimated to be $130 \mathrm{ppb}$ based on the simulated [CO] over the open ocean west of Los Angeles. The observed diurnal profile of OA / $\triangle \mathrm{CO}$ during SOAR exhibits a distinct peak around midday, corresponding to the peak in photochemical activity. This indicates a substantial influence of SOA production on the total OA concentration (Fig. 5; Docherty et al., 2008). The simulated OA / $\triangle \mathrm{CO}$ diurnal profiles around Riverside for the SOM-high simulations are most consistent with the observations, exhibiting a distinct peak around midday that is similar to the observations (Fig. 5). Unlike the observations, the diurnal OA / $\triangle \mathrm{CO}$ profile for the SOM-no simulation exhibits almost no increase during midday and the SOM-low simulation exhibits only a slightly larger daytime increase. The slope of a onesided linear fit to a graph of the observed [OA] vs. [CO] during daytime (10:00 to 20:00 LT is $69 \pm 2 \mu \mathrm{g} \mathrm{m}^{-3} \mathrm{ppm}^{-1}$ (Fig. 5) when constrained to go through the assumed 


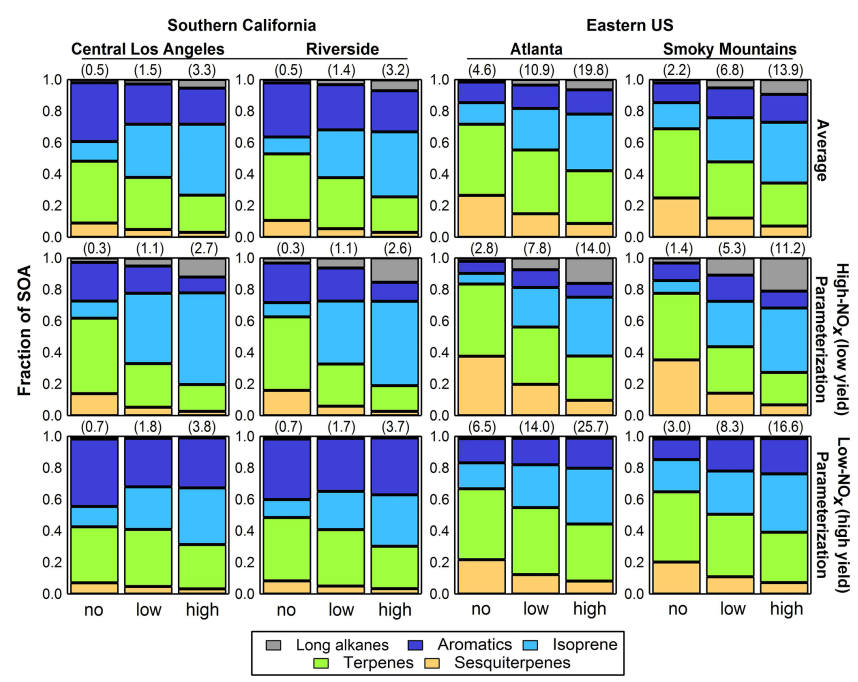

Figure 4. Bar charts showing the fractional contribution from the various VOC precursor classes to the total simulated SOA for two locations in SoCAB (central Los Angeles and Riverside) and two in the eastern US (Atlanta and the Smoky Mountains). Results are shown for (top) average, (middle) high- $\mathrm{NO}_{x}$, low-yield and (bottom) low- $\mathrm{NO}_{x}$, high-yield simulations. Each panel shows results from the 14-day average (left-to-right) SOM-no, SOM-low and SOM-high simulations. The average SOA concentration (in $\mu \mathrm{g} \mathrm{m}^{-3}$ ) is for each location and simulation is given in parentheses above each panel.

$[\mathrm{CO}]_{\text {bgd }}$. This can be compared with the simulation results, which have constrained slopes of $23.0 \pm 0.4,34.0 \pm 0.8$ and $55 \pm 2 \mu \mathrm{g} \mathrm{m}^{-3} \mathrm{ppm}^{-1}$ for SOM-no, SOM-low and SOMhigh, respectively (Fig. $5 \mathrm{~g}-\mathrm{i}$ ). Clearly the SOM-high simulations are in best overall agreement with the SOAR observations. However, the maximum in the simulated OA / $\triangle \mathrm{CO}$ peaks at a smaller value than was observed. The simulated peak also occurs slightly earlier than the maximum in the observations, which could be due to discrepancies in the transport to the Riverside site or to too fast SOA formation in the model. Nonetheless, these results clearly indicate that accounting for vapor wall losses has the potential to reconcile simulated SOA diurnal behavior with observations. Alternatively or complementarily, daytime increases in the OA / $\triangle \mathrm{CO}$ ratio from SOA production can be achieved with the introduction of additional SOA precursor material such as S/IVOCs (Zhao et al., 2014; Hayes et al., 2015), which are not considered here. The addition of S/IVOCs would increase the daytime OA / $\triangle \mathrm{CO}$ for all of the simulations. The magnitude of the increase would depend on the amount of added S/IVOCs and the properties assigned to the S/IVOCs regarding their SOA formation timescale and yield. Consideration of SOA from S/IVOCs in the SoCAB using the SOM framework will be the subject of future work.

\subsection{SOA Composition}

\subsubsection{Source/VOC precursor dependence}

Accounting for vapor wall losses leads to regionally specific changes in the simulated contributions from the different VOC classes (e.g. TRP1, ARO1) to the SOA burden, as illustrated in Fig. 4 for two sites in SoCAB (central Los Angeles and Riverside) and two in the eastern US (Atlanta and the Smoky Mountains). Focusing first on contributions from the biogenic VOCs, at all locations accounting for vapor wall losses leads to an increase in the fractional contribution of isoprene SOA, typically at the expense of terpene and sesquiterpene SOA. This is true for both the low- and high$\mathrm{NO}_{x}$ simulations. Recent observations suggest that isoprene SOA produced via the low-NO IEPOX (isoprene epoxydiol) pathway can be uniquely identified from analysis of aerosol mass spectrometer measurements when the relative contribution is sufficiently large ( $>\sim 5 \%$; e.g. Budisulistiorini et al., 2013; Hu et al., 2015). This observed IEPOX SOA accounts for around $30 \%$ (May) and $40 \%$ (August) of total SOA or around $20 \%$ (May) and $30 \%$ (August) of total OA in Atlanta in the summer (Xu et al., 2015a), albeit not during the same time period as simulated here. IEPOX SOA was also found to account for $17 \%$ of total OA at a rural site in Alabama in 2013 (Hu et al., 2015). The SOM-low and SOM-high simulation results for Atlanta are most consistent with the observations, with a predicted isoprene SOA fraction of 27 and $35 \%$, respectively, compared to only $17 \%$ for the SOM-no simulations and where the reported values are for the simulations that use the low- $\mathrm{NO}_{x}$ parameterizations since this is the pathway that leads to IEPOX SOA. The related isoprene OA fractions are 10, 21 and $31 \%$ for the SOM-no, -low and -high simulations, respectively. (These isoprene SOA fractions change only marginally for SOM-low and SOM-high simulations when the high- $\mathrm{NO}_{x}$ parameterizations are used, to 25 and $37 \%$, respectively. The SOM-no simulations exhibit somewhat greater sensitivity to the $\mathrm{NO}_{x}$ parameterization, with the high- $\mathrm{NO}_{x}$ parameterization giving an SOA fraction of $7 \%$.)

In SoCAB, the predicted average isoprene SOA fraction in central LA is relatively large for the SOM-low (36\%) and SOM-high (47\%) simulations, compared to the SOM-no simulations $(12 \%)$. There is a large difference in SoCAB between the simulations that use the low- $\mathrm{NO}_{x}$ and high- $\mathrm{NO}_{x}$ parameterizations, with the isoprene SOA fractions being much larger with the high- $\mathrm{NO}_{x}$ parameterizations (e.g. $58 \%$ for high- $\mathrm{NO}_{x}$ vs. $36 \%$ for low-NO $\mathrm{N}_{x}$ for the SOM-high simulations). Measurements at Pasadena during the 2010 CalNex study did not distinctly identify IEPOX SOA, which is interpreted as the IEPOX SOA contribution being lower than $\sim 5 \%$ of the OA (Hu et al., 2015). It is possible that additional isoprene SOA had been formed under higher $\mathrm{NO}_{x}$ conditions (compared to the southeast US) such that it is chemically different from IEPOX-SOA and was not identi- 

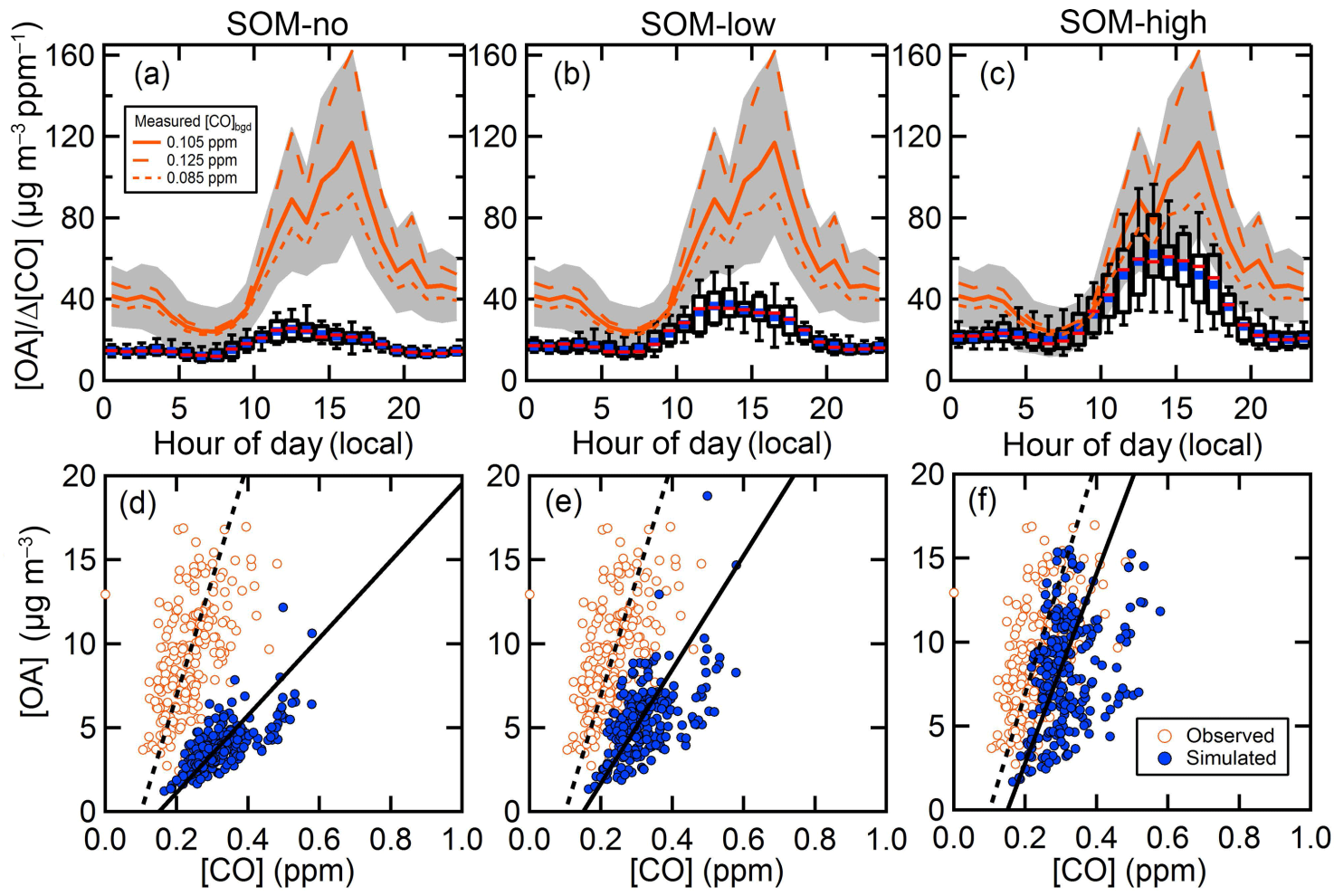

Figure 5. Simulated and observed diurnal profiles for the OA / $\triangle \mathrm{CO}$ ratio (top panels) at Riverside, CA, during the SOAR-2005 campaign for (a) SOM-no, (b) SOM-low and (c) SOM-high simulations. For the observations, the mean (solid orange line) and the $1 \sigma$ variability range (grey band) are shown for $[\mathrm{CO}]_{b g d}=0.105 \mathrm{ppm}$, and only mean values are shown for $[\mathrm{CO}]_{b g d}=0.085 \mathrm{ppm}$ (short dashed orange line) and $[\mathrm{CO}]_{\mathrm{bgd}}=0.125 \mathrm{ppm}$ (long dashed orange line). For the simulations, box and whisker plots are shown with the median (red - ), mean (blue squares), lower and upper quartile (boxes), and 9th and 91st percentile (whiskers). The bottom panels (e-f) show scatter plots of [OA] vs. [CO] for both the ambient measurements (open orange circles) and for the model results (blue circles) for daytime hours (10:00-20:00 LT). The lines are linear fits where the $x$ axis intercept has been constrained to go through the assumed $[\mathrm{CO}]_{\text {bgd }}$ (dashed $=$ observed; solid $=$ model). The derived slopes are $69 \pm 2$ (observed), $23.0 \pm 0.4$ (SOM-no), $34.0 \pm 0.8$ (SOM-low) and $55 \pm 2$ (SOM-high) $\mu \mathrm{g} \mathrm{m}^{-3} \mathrm{ppm}^{-1} \mathrm{and} \mathrm{where}^{-1}$ the uncertainties are fit errors.

fied as a uniquely isoprene-derived SOA component, instead contributing generically to the overall oxygenated OA pool. The concentration of isoprene SOA from specific high- $\mathrm{NO}_{x}$ pathways may, however, be limited at higher temperatures, such as found in summertime Pasadena, due to thermal decomposition of intermediate gas-phase species (Worton et al., 2013), although it is not clear to what extent this influenced the CalNex observations or would have affected the model results had it been explicitly considered. Additionally, it should be kept in mind that the ambient $\mathrm{NO}_{x}$ concentrations in SoCAB have decreased substantially from 2005 to 2013 (Russell et al., 2012). Thus, although the CalNex measurements do not provide direct support for such a large isoprene SOA fraction, they also do not rule it out.

While the predicted isoprene SOA fraction increased, the predicted terpene and sesquiterpene SOA fractions decreased in the simulations that accounted for vapor wall losses. Additionally, the terpene SOA / sesquiterpene SOA ratio increased at all locations for the SOM-low and SOM-high simulations, in large part because the sesquiterpene yield is already large and thus accounting for vapor wall losses has a limited influence on the simulated sesquiterpene SOA concentrations.

There are some changes in the anthropogenic fraction of SOA when vapor wall losses are accounted for. The anthropogenic fraction of SOA is defined here as the sum of the SOA from long alkanes and aromatics, which are emitted from combustion of fossil fuels, divided by the sum of the total SOA, which additionally includes SOA from isoprene, monoterpenes and sesquiterpenes emitted by trees, plants and other natural sources. The ${ }^{14} \mathrm{C}$ isotopic signature of fossil-derived VOCs is different from that of biogenically derived VOCs, and thus their respective contributions to SOA can be partially constrained via experimental analysis of the ${ }^{14} \mathrm{C}$ content of OA (Zotter et al., 2014). We assume the anthropogenic fraction is equivalent to the fossil fraction of SOA (termed $\left.F_{\text {SOA,fossil }}\right)$. At the two eastern US sites (Atlanta and Smokey Mountains) the average $F_{\text {SOA,fossil }}$ increases slightly from $14 \%$ (SOM-no) to $22 \%$ (SOM-low) and $25 \%$ (SOM-high). At the two SoCAB sites (downtown LA and Riverside) the predicted average $F_{\text {SOA,fossil decreases }}$ 
slightly, from 35 (SOM-no) to $29 \%$ (SOM-low) and $30 \%$ (SOM-high), respectively. In SoCAB the $F_{\text {SOA,fossil values }}$ differ between the low- and high- $\mathrm{NO}_{x}$ parameterizations, with $F_{\text {SOA,fossil }}$ typically larger for the low- $\mathrm{NO}_{x}$ parameterizations (e.g. $35 \%$ for low- $\mathrm{NO}_{x}$ and $25 \%$ for high- $\mathrm{NO}_{x}$ ). In the eastern US, the predicted $F_{\mathrm{SOA} \text {,fossil }}$ exhibit a stronger response to vapor wall losses for the high- $\mathrm{NO}_{x}$ parameterization than the low- $\mathrm{NO}_{x}$ parameterization, although the absolute values are reasonably similar. Of the anthropogenic SOA (aromatics + alkanes), the high- $\mathrm{NO}_{x}$ parameterizations indicate an increasing alkane SOA fraction as vapor wall losses are accounted for in both regions. In contrast, the low- $\mathrm{NO}_{x}$ parameterizations indicate minor contributions from alkane SOA for all of the simulations. In general, chamber SOA yields from aromatic compounds are larger for low- $\mathrm{NO}_{x}$ conditions ( $\mathrm{Ng}$ et al., 2007a), which could help to explain these differences.

The SoCAB $F_{\text {SOA,fossil }}$ values can be compared with estimates of the fossil fraction of "oxidized organic carbon" $\left(F_{\mathrm{OOC}, \text { fossil }}\right)$ from measurements made during CalNex in Pasadena (Zotter et al., 2014). It should be noted that while $F_{\text {SOA,fossil }}$ includes contributions from both oxygen and car-

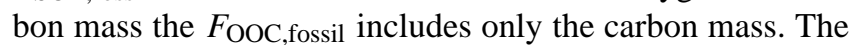
fossil fraction of secondary organic carbon (SOC) can be calculated from the simulated SOA concentrations by accounting for the differences in the $\mathrm{O}: \mathrm{C}$ atomic ratios of the different SOA types to facilitate more direct comparison between the simulations and observations. Specifically, the SOC mass concentration $\left(C_{\mathrm{SOC}}\right)$ is related to the SOA mass concentration $\left(C_{\mathrm{SOA}}\right)$ for a given SOA type through the relationship:

$$
\begin{aligned}
C_{\mathrm{SOC}} & =C_{\mathrm{SOA}} \times \frac{N_{\mathrm{C}} \times \mathrm{MW}_{\mathrm{C}}}{\mathrm{MW}_{\mathrm{SOA}}} \\
& =\frac{N_{\mathrm{C}} \times \mathrm{MW}_{\mathrm{C}}}{N_{\mathrm{C}} \times \mathrm{MW}_{\mathrm{C}}+N_{\mathrm{O}} \times \mathrm{MW}_{\mathrm{O}}+N_{\mathrm{H}} \times \mathrm{MW}_{\mathrm{H}}} \\
& =\frac{C_{\mathrm{SOA}}}{\frac{4}{3}(\mathrm{O}: \mathrm{C})+\frac{1}{12}(\mathrm{H}: \mathrm{C})+1},
\end{aligned}
$$

where $\mathrm{MW}_{\mathrm{C}}, \mathrm{MW}_{\mathrm{O}}, \mathrm{MW}_{\mathrm{H}}$ are the molecular weights of carbon, oxygen and hydrogen atoms, respectively. The $\mathrm{O}: \mathrm{C}$ and $\mathrm{H}: \mathrm{C}$ values of the different SOA types are not constant in the SOM due to the continuous evolution of the product distribution. However, for a given SOA type the simulated O : C and $\mathrm{H}$ : C values vary over a relatively narrow range (Cappa et al., 2013) and thus an average value can be used. The resulting

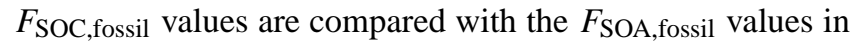

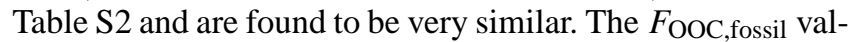
ues were determined from ${ }^{14} \mathrm{C}$ analysis of particles collected on filters to allow for determination of the fossil fraction of the total carbonaceous material coupled with positive matrix factorization to allow separation of the contributions from the various fossil and non-fossil POA and SOA sources. The uncertainty in the fossil fraction of total OC was reported as $9 \%$; the uncertainty in the $F_{\mathrm{OOC} \text {,fossil will be larger. Zotter et }}$ al. (2014) determined the nighttime $F_{\mathrm{OOC} \text {,fossil was smaller }}$ than the peak daytime value and that the $24 \mathrm{~h}$ average bestestimate $F_{\mathrm{OOC} \text {,fossil }}=44 \%$. This is somewhat larger than the average predicted $F_{\text {SOC,fossil }}$ (e.g. $31 \%$ for SOM-high). The difference between the observed $F_{\mathrm{OOC} \text {,fossil and predicted }}$ $F_{\text {SOC,fossil }}$ could indicate a role for SOA formed from fossilderived S/IVOC species in the atmosphere but which are not considered here.

\subsubsection{The oxygen-to-carbon ratio}

The O:C atomic ratios of the SOA have been calculated from the simulated distributions of compounds in $N_{\mathrm{C}}$ and $N_{\mathrm{O}}$ space; the $\mathrm{O}: \mathrm{C}$ atomic ratio is an inherent property of the SOM model and $(\mathrm{O}: \mathrm{C})_{\text {SOA }}$ values from box model simulations using SOM exhibit generally good agreement with observations (Cappa and Wilson, 2012; Cappa et al., 2013). Few air quality models attempt to simulate $\mathrm{O}: \mathrm{C}$ ratios for SOA (e.g. Murphy et al., 2011), although a dramatic expansion in observations of $\mathrm{O}: \mathrm{C}$ ratios for ambient $\mathrm{OA}$ has recently occurred (Ng et al., 2011; Canagaratna et al., 2015; Chen et al., 2015). Comparison between intensive properties such as $\mathrm{O}: \mathrm{C}$, in addition to absolute $\mathrm{OA}$ concentrations, can provide further constraints on the transformation processes and $\mathrm{OA}$ sources in a given region. The simulated $(\mathrm{O}: \mathrm{C})_{\mathrm{SOA}}$ in the SOM-no simulations are generally larger in SoCAB than in the eastern US (Fig. 6). The simulated $(\mathrm{O}: \mathrm{C})_{\mathrm{SOA}}$ from isoprene and aromatics individually are larger than those from mono- or sesquiterpenes due, in large part, to the smaller carbon backbone and the need to add more oxygens to produce sufficiently low volatility species that partition substantially to the particle phase (Chhabra et al., 2011; Cappa and Wilson, 2012; Tkacik et al., 2012). Thus, the larger $(\mathrm{O}: \mathrm{C})_{\mathrm{SOA}}$ in SoCAB results from larger relative contributions from isoprene and aromatic compounds to the total SOA burden in this region. The $(\mathrm{O}: \mathrm{C})_{\mathrm{SOA}}$ is also generally larger in regions where SOA concentrations are smaller. This may reflect some relationship between SOA source and concentration, but it also reflects the role that continued multigenerational oxidation has on the SOA composition, since lower concentrations can reflect greater dilution and overall more aged SOA.

The $(\mathrm{O}: \mathrm{C})_{\text {SOA }}$ for the SOM-low and SOM-high simulations are substantially larger than that from the SOM-no simulations in both SoCAB and the eastern US (Fig. 6). This reflects two phenomena: (i) the increased relative contribution of isoprene to the total simulated SOA burden in the SOMlow and SOM-high simulations and (ii) differences in the SOM chemical pathways (i.e. the SOM parameters) that lead to the production of condensed-phase material between the parameterizations that do/do not include vapor wall losses. The influence of the latter has been confirmed through box model simulations, although the exact behavior is both precursor specific and somewhat dependent on the reaction conditions (e.g. $[\mathrm{OH}]$ and the initial precursor concentration). Overall, the former effect likely dominates since the differ- 
(O:C)SOA, no
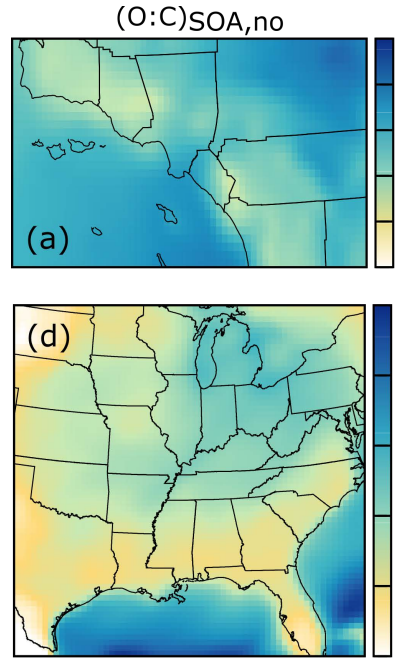
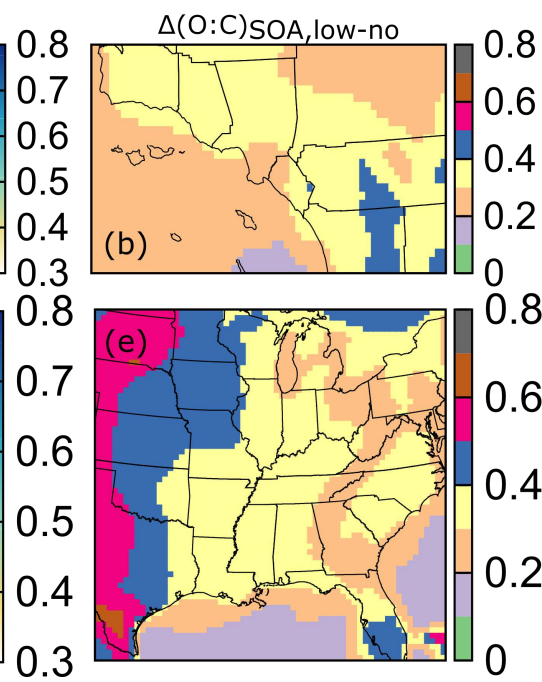
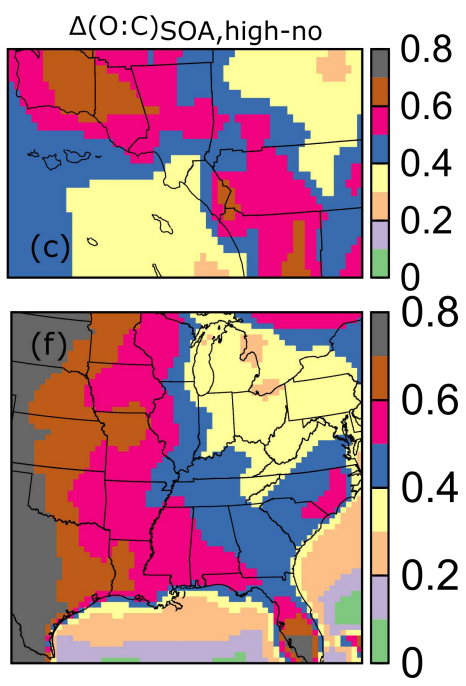

Figure 6. 14-day averaged $\mathrm{O}: \mathrm{C}$ atomic ratios for SOA for (a) SoCAB and (d) the eastern US for the SOM-no simulations. The difference in $\mathrm{O}: \mathrm{C}$ between the SOM-low or SOM-high and SOM-no simulations, termed $\Delta(\mathrm{O}: \mathrm{C})$, is shown in panels $(\mathbf{b}-\mathbf{c})$ for SoCAB and $(\mathbf{e}-\mathbf{f})$ for the eastern US.

ence in simulated $(\mathrm{O}: \mathrm{C})_{\text {SOA }}$ between isoprene and monoterpenes is substantial (Jathar et al., 2015a).

The simulated $\mathrm{O}: \mathrm{C}$ for the total OA also differs substantially between simulations (Fig. 7), especially in regions where the simulated increase in $f_{\mathrm{SOA}}$ is largest (Fig. 2). The simulated $(\mathrm{O}: \mathrm{C})_{\text {total }}$ in both the SoCAB and eastern US increases substantially when vapor wall losses are accounted for. For example, the simulated $(\mathrm{O}: \mathrm{C})_{\text {total }}$ values at Riverside were 0.22, 0.3 and 0.42 and at Atlanta were 0.45, 0.65 and 0.85 for SOM-no, SOM-low and SOM-high simulations, respectively. The increase in $(\mathrm{O}: \mathrm{C})_{\text {total }}$ is mostly driven by an associated increase in $f_{\text {SOA }}$. The $(\mathrm{O}: \mathrm{C})_{\text {total }}$ value is a weighted average of the $(\mathrm{O}: \mathrm{C})_{\mathrm{SOA}}$ and $(\mathrm{O}: \mathrm{C})_{\mathrm{POA}}$, with $(\mathrm{O}: \mathrm{C})_{\text {total }}=\left(n_{\mathrm{O}, \mathrm{SOA}}+n_{\mathrm{O}, \mathrm{POA}}\right) /\left(n_{\mathrm{C}, \mathrm{SOA}}+n_{\mathrm{C}, \mathrm{POA}}\right)$ where $n_{\mathrm{O}}$ and $n_{\mathrm{C}}$ indicate the number of oxygen and carbon atoms, respectively, that comprise all SOA types and POA. For conceptual purposes, this exact expression for $(\mathrm{O}: \mathrm{C})_{\text {total }}$ can be approximated as $(\mathrm{O}: \mathrm{C})_{\text {total }} \sim f_{\mathrm{SOA}}(\mathrm{O}: \mathrm{C})_{\mathrm{SOA}}+(1-$ $\left.f_{\mathrm{SOA}}\right)(\mathrm{O}: \mathrm{C})_{\mathrm{POA}}$, where $(\mathrm{O}: \mathrm{C})_{\mathrm{SOA}}$ represents the average over the different SOA types. Thus, changes in $f_{\mathrm{SOA}}$ lead to changes in $(\mathrm{O}: \mathrm{C})_{\text {total }}$, with some additional smaller changes due to variation in the weighted average $(\mathrm{O}: \mathrm{C})_{\text {SOA }}$ between the various simulations (since each SOA type has a particular $\mathrm{O}: \mathrm{C}$ range). The predicted eastern US $(\mathrm{O}: \mathrm{C})_{\text {total }}$ are generally larger than in $\mathrm{SoCAB}$ due to the larger $f_{\mathrm{SOA}}$ in the eastern US and since $(\mathrm{O}: \mathrm{C})_{\mathrm{SOA}}$ is typically larger than $(\mathrm{O}: \mathrm{C})_{\mathrm{POA}}$. For example, the average $(\mathrm{O}: \mathrm{C})_{\text {total }}$ in Atlanta for the SOM-no simulations was 0.4 whereas it was 0.22 in Riverside.

The simulated results at Riverside can be compared with bulk, campaign average $(\mathrm{O}: \mathrm{C})_{\text {total }}$ values measured during the SOAR campaign using an Aerodyne high-resolution time-of-flight aerosol mass spectrometer (HR-AMS), which determines $(\mathrm{O}: \mathrm{C})_{\text {total }}$ with an absolute uncertainty of $\pm 30 \%$ but with very high precision (Docherty et al., 2008; Dzepina et al., 2009). Values reported here have been corrected according to Canagaratna et al. (2015). The campaign-average observed $(\mathrm{O}: \mathrm{C})_{\text {total }}$ was $\sim 0.45$. The SOM-high $(\mathrm{O}: \mathrm{C})_{\text {total }}$ is in very good agreement with the observations, whereas $(\mathrm{O}: \mathrm{C})_{\text {total }}$ is too small for both SOM-no and SOM-low. This good correspondence is, of course, sensitive to the assumed $(\mathrm{O}: \mathrm{C})_{\mathrm{POA}}$, here 0.2 based on (Ng et al., 2011). If a smaller $(\mathrm{O}: \mathrm{C})_{\mathrm{POA}}$ had been assumed, then either a greater amount of SOA would be required or the simulated $(\mathrm{O}: \mathrm{C})_{\mathrm{SOA}}$ would need to be larger to match the SOAR measurements. Docherty et al. (2011) determined there were three POA types during SOAR, with a weighted-average-corrected $\mathrm{O}: \mathrm{C}=0.095$, suggesting that the assumed 0.2 is too large. In contrast, Hayes et al. (2013) determined a weighted-averagecorrected $\mathrm{O}: \mathrm{C}=0.25$ for the three POA types identified at Pasadena during CalNex. It has been suggested that at least some of the difference in the $(\mathrm{O}: \mathrm{C})_{\mathrm{POA}}$ between SOAR and CalNex results from greater heterogeneous ageing of the Pasadena POA. Regardless of the exact $(\mathrm{O}: \mathrm{C})_{\text {POA }}$, a strong improvement in the model-measurement agreement when vapor wall losses are accounted for is evident. Of additional consideration is the diurnal dependence of the $(\mathrm{O}: \mathrm{C})_{\text {total }}$. The observed $(\mathrm{O}: \mathrm{C})_{\text {total }}$ exhibited a distinct diurnal dependence, with low values at night, a minimum at $\sim 7: 00 \mathrm{LT}$ and maximum values around midday (Fig. 8). The simulated $(\mathrm{O}: \mathrm{C})_{\text {total }}$ diurnal profile for the SOM-high simulations agrees reasonably well with the SOAR observations in terms of both the magnitude of the day-night difference and the absolute $(\mathrm{O}: \mathrm{C})_{\text {total }}$ (Fig. 8). In contrast, both the SOM-no and SOM-low exhibit only minor variations with time-of-day due to the controlling influence of $(\mathrm{O}: \mathrm{C})_{\mathrm{POA}}$. 

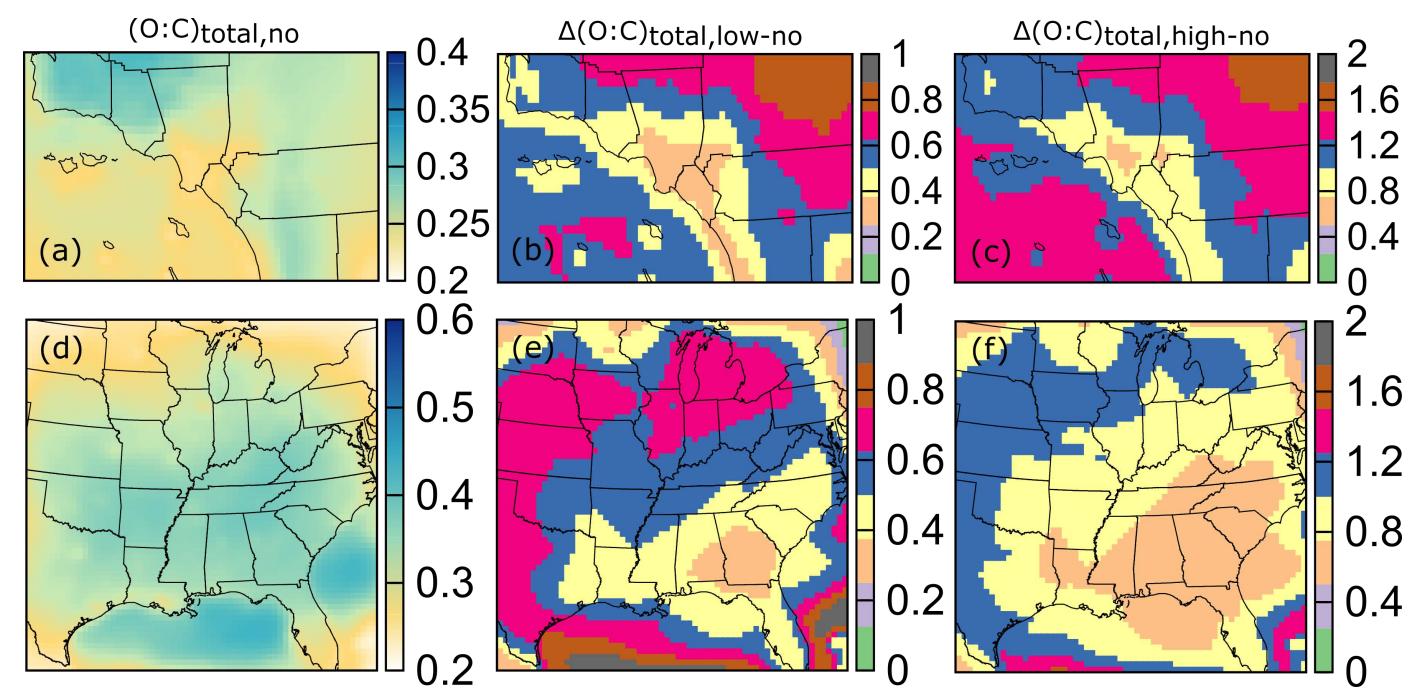

Figure 7. 14-day averaged $\mathrm{O}: \mathrm{C}$ atomic ratios for total OA (POA + SOA) for (a) SoCAB and (d) the eastern US for the SOM-no simulations. The normalized difference in $\mathrm{O}: \mathrm{C}, \Delta(\mathrm{O}: \mathrm{C})$, between the SOM-low or SOM-high and SOM-no simulations, where $\Delta(\mathrm{O}: \mathrm{C})$ is defined as $\left.\left((\mathrm{O}: \mathrm{C})_{\mathrm{SOM}-\text { low/high }}-(\mathrm{O}: \mathrm{C})_{\mathrm{SOM}-\mathrm{no}}\right) /(\mathrm{O}: \mathrm{C})_{\mathrm{SOM}-\mathrm{no}}\right)$, is shown in panels $(\mathbf{b}-\mathbf{c})$ for SoCAB and $(\mathbf{e}-\mathbf{f})$ for the eastern US. In all cases, the O : C for POA was assumed to be 0.2 .

The simulated $(\mathrm{O}: \mathrm{C})_{\text {total }}$ values in the eastern US can also be compared with recent observations, with the caveat that in this case the measurements were not made over the same time-period as the simulations were run. Nonetheless, measurements made in summer and winter of 2012 and 2013 at various locations in Alabama and Georgia indicate the $\mathrm{O}: \mathrm{C}$ values for total OA were relatively constant, around 0.6-0.7, although it should be noted that these values were estimated from measurements made using an Aerodyne aerosol chemical speciation monitor, which increases the uncertainty (Xu et al., 2015b). Measurements made around the southeast US using an HR-AMS onboard the NASA DC8 as part of the SEAC4RS field study indicate the average $(\mathrm{O}: \mathrm{C})_{\text {total }}=0.8$ when the plane was flying below $1 \mathrm{~km}$ (SEAC4RS, 2014). As noted above, the simulated $(\mathrm{O}: \mathrm{C})_{\text {total }}$ around Atlanta was 0.45 for SOM-no, increasing to $\sim 0.65$ for SOM-low and $\sim 0.85$ for SOM-high. As with the SoCAB comparison, the general level of agreement between the observed and simulated $(\mathrm{O}: \mathrm{C})_{\text {tot }}$ was improved when vapor wall losses were accounted for.

The above simulations included SOA only from VOCs, neglecting contributions from S/IVOCs including oxidation of semi-volatile POA vapors. S/IVOCs and semi-volatile POA vapors are likely $\geq \mathrm{C}_{14}$ carbon species (Jathar et al., 2014; Zhao et al., 2014). As such, little added oxygen is required to produce low-volatility species that will form SOA. Since these species also have relatively large number of carbon atoms, the $\mathrm{O}: \mathrm{C}$ of the SOA formed from them will be relatively small, most likely with $(\mathrm{O}: \mathrm{C})_{\mathrm{S} / \mathrm{IVOC}}<0.2$ in the absence of strong heterogeneous oxidation (Cappa and Wilson, 2012; Tkacik et al., 2012); note that this range is lower than what was assumed for the non-volatile POA here. Conse- quently, had S/IVOCs been included in the simulations the $(\mathrm{O}: \mathrm{C})_{\text {total }}$ would have likely decreased. The magnitude of the decrease would depend on the exact extent to which the S/IVOCs contributed to the overall SOA burden, the extent to which the simulated POA decreased (due to the semivolatile treatment), and on the simulated $(\mathrm{O}: \mathrm{C})_{\text {S/IVOC. In }}$ the limit that SOA from S/IVOCs dominates the SOA budget, very little variation in the $(\mathrm{O}: \mathrm{C})_{\text {total }}$ ratio with time of day would have likely been predicted because $(\mathrm{O}: \mathrm{C})_{\mathrm{POA}} \sim$ $(\mathrm{O}: \mathrm{C})_{\text {S/IVOC }}$. Additionally, the simulated daytime $(\mathrm{O}: \mathrm{C})_{\text {total }}$ values would have likely been close to 0.2 . A lack of diurnal variability and a small $(\mathrm{O}: \mathrm{C})_{\text {total }}$ would both be inconsistent with the SOAR observations. Consequently, this implies that accounting for vapor wall losses has a stronger potential to allow for simultaneous reconciliation of the diurnal behavior of both the simulated OA / $\triangle \mathrm{CO}$ and $(\mathrm{O}: \mathrm{C})_{\text {total }}$ with observations than does consideration of oxidation of S/IVOCs alone. This is not to say that S/IVOC contributions to the SOA and total OA burden are not important, only that it seems unlikely that they could dominate the SOA budget. Ultimately, it seems likely that consideration of both vapor wall losses (as done here) and of SOA from S/IVOCs will be necessary to fully close the model-measurement gap.

\section{Conclusions}

The influence of chamber vapor wall losses on simulated SOA concentrations and properties has been assessed. The statistical oxidation model was used to parameterize SOA formation from laboratory chamber experiments both with and without accounting for vapor wall losses using data from experiments conducted under both high- $\mathrm{NO}_{x}$ and low- $\mathrm{NO}_{x}$ 

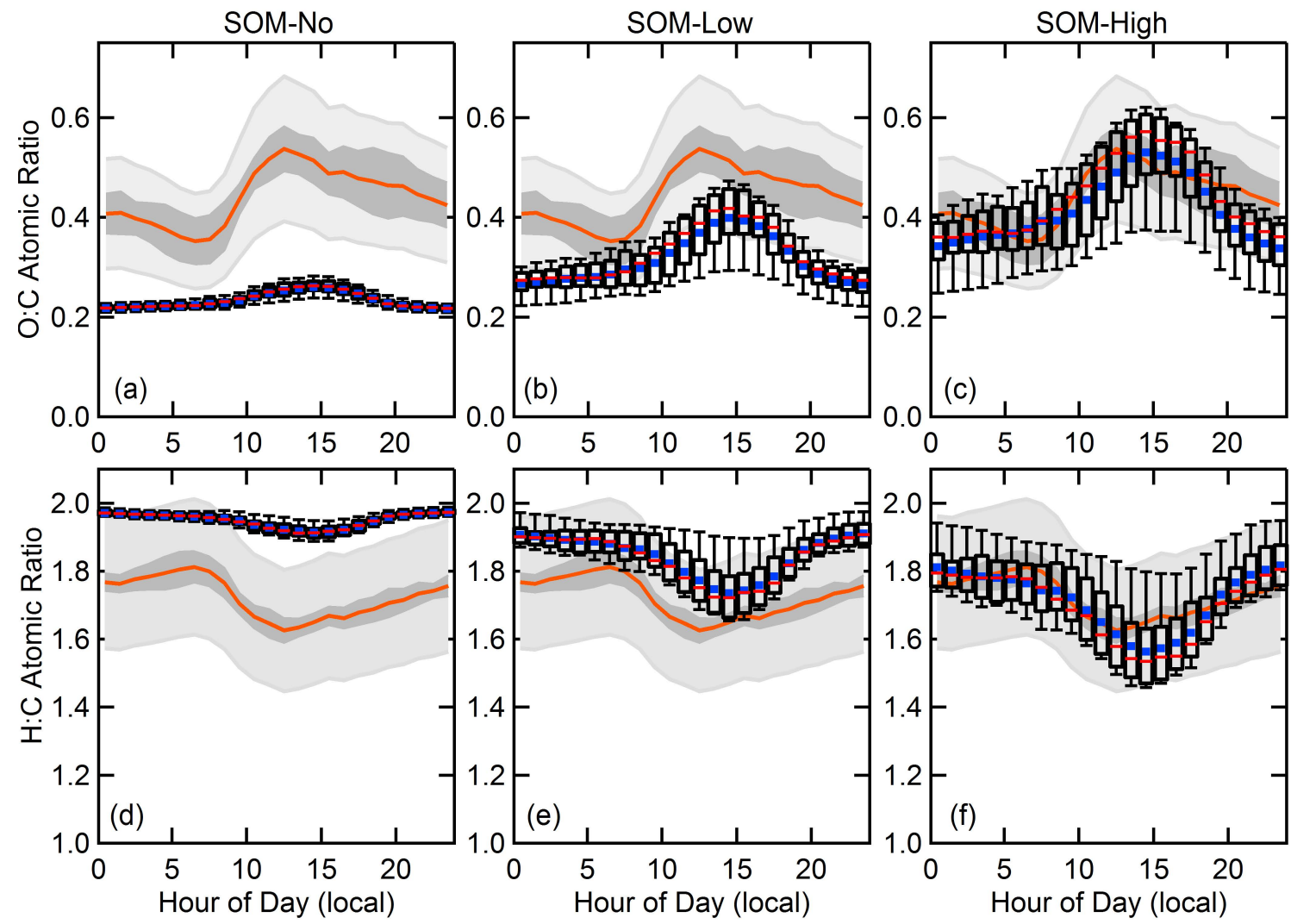

Figure 8. Simulated and observed diurnal profiles for the total OA O : C (a, b, c) and $\mathrm{H}: \mathrm{C}(\mathbf{d}, \mathbf{e}, \mathbf{f})$ atomic ratios at Riverside, CA, during the SOAR-2005 campaign for (a, d) SOM-no, (b, e) SOM-low and (c, f) SOM-high simulations. For the observations, the mean (orange line) and the $1 \sigma$ variability range (dark grey band) are shown along with bands indicating the measurement uncertainty (light grey band), taken as $\pm 28 \%$ for O : C and $13 \%$ for $\mathrm{H}: \mathrm{C}$ (Canagaratna et al., 2015). Observed values have been corrected according to Canagaratna et al. (2015). For the simulations, box and whisker plots are shown with the median (red -), lower and upper quartile (boxes), and 9th and 91st percentile (whiskers). For reference, the assumed $\mathrm{O}: \mathrm{C}$ for POA was 0.2 and for $\mathrm{H}: \mathrm{C}$ was 2.0.

conditions. "Low" and a "high" vapor wall-loss cases were considered in addition to the "no" vapor wall-loss case. The best-fit SOM parameters under these different conditions were used as input to SOA simulations in the 3-D UCD/CIT regional air quality model, in which SOM has been recently implemented (Jathar et al., 2015a). Simulations were run for southern California and for the eastern US. Explicit accounting for vapor wall losses led to increases in simulated SOA concentrations, by a factor of $\sim 2-5$ for the "low" simulations and $\sim 5-10$ for the "high" simulations. The magnitude of the increase was inversely related to the simulated absolute SOA concentration. This suggests that the extent to which SOA concentrations are underpredicted may be greater in more remote regions.

This increase in simulated SOA when vapor wall losses are accounted for leads to a substantial increase in the simulated SOA fraction of total OA. This is especially seen in So$\mathrm{CAB}$ where $f_{\mathrm{SOA}}$ is very small for the base model but $>50 \%$ for the simulations that account for vapor wall losses. The simulated $f_{\mathrm{SOA}}$ in SoCAB is found to agree reasonably well with observations when vapor wall losses are accounted for.
Comparison of the $\mathrm{OA} / \triangle \mathrm{CO}$ from the SoCAB simulations with observations form the SOAR campaign (Docherty et al., 2008) indicate that accounting for vapor wall losses leads to substantially improved agreement in terms of the diurnal behavior, in particular the magnitude of the daytime increase in $\mathrm{OA} / \triangle \mathrm{CO}$. Accounting for vapor wall losses also leads to location-specific changes in the major contributing VOC precursors to the SOA burden. In general, accounting for vapor wall losses leads to an increase in the predicted relative contribution of isoprene SOA and a decrease in the relative contribution of monoterpene and sesquiterpene SOA. The relative contribution of total anthropogenic VOCs to SOA is reasonably insensitive to vapor wall losses, especially in So$\mathrm{CAB}$, although the apportionment between aromatic VOCs and alkanes does vary with vapor wall losses. The simulated anthropogenic SOA fraction is, however, somewhat smaller than suggested by ${ }^{14} \mathrm{C}$ observations during CalNex (Zotter et al., 2014). In general, the simulated $\mathrm{O}: \mathrm{C}$ atomic ratio of the SOA increased for the low and high vapor wall-loss simulations, compared to the base case. The simulated $\mathrm{O}: \mathrm{C}$ of the total $\mathrm{OA}(\mathrm{SOA}+\mathrm{POA})$ in both SoCAB and the eastern US 
are in better agreement with observations when vapor wall losses are accounted for.

Overall, the generally improved model performance when vapor wall losses are accounted for - in terms of both absolute and relative concentrations and in terms of SOA properties - suggests that accounting for this chamber effect in atmospheric simulations of SOA is important, although certainly requiring further examination. Our results qualitatively agree with other recent efforts to assess the influence of vapor wall losses on ambient SOA concentrations (Baker et al., 2015; Hayes et al., 2015), but as our accounting for vapor wall loss is inherent in the SOA parameterization the simulations here serve to provide a more robust assessment. The results presented here additionally suggest that there may be no need to invoke ad hoc "ageing" schemes for aromatics (Tsimpidi et al., 2010) to achieve increases in simulated SOA concentrations in urban environments. Further, these results suggest that the contribution of S/IVOCs to urban SOA might be somewhat limited, albeit still important, although this issue certainly requires further investigation.

\section{The Supplement related to this article is available online at doi:10.5194/acp-16-3041-2016-supplement.}

Author contributions. The manuscript was written through contributions of all authors. Christopher D. Cappa, Shantanu H. Jathar, Michael J. Kleeman, John H. Seinfeld and Anthony S. Wexler designed the project. Shantanu H. Jathar and Michael J. Kleeman carried out the simulations. Christopher D. Cappa determined model parameters using laboratory data collected by John H. Seinfeld. Kenneth S. Docherty and Jose L. Jimenez collected and processed the SOAR data. All authors have given approval to the final version of the manuscript.

Acknowledgements. The authors thank Pedro Campuzano-Jost for the SEAC4RS data. This study was funded by the California Air Resources Board, contract 12-312 and NOAA grant NA13OAR4310058. Jose L. Jimenez was supported by CARB 11-305 and EPA STAR 83587701-0. This manuscript has not been reviewed by the funding agencies and no endorsement should be inferred.

Edited by: K. Lehtinen

\section{References}

Baker, K. R., Carlton, A. G., Kleindienst, T. E., Offenberg, J. H., Beaver, M. R., Gentner, D. R., Goldstein, A. H., Hayes, P. L., Jimenez, J. L., Gilman, J. B., de Gouw, J. A., Woody, M. C., Pye, H. O. T., Kelly, J. T., Lewandowski, M., Jaoui, M., Stevens, P.
S., Brune, W. H., Lin, Y.-H., Rubitschun, C. L., and Surratt, J. D.: Gas and aerosol carbon in California: comparison of measurements and model predictions in Pasadena and Bakersfield, Atmos. Chem. Phys., 15, 5243-5258, doi:10.5194/acp-15-52432015, 2015.

Budisulistiorini, S. H., Canagaratna, M. R., Croteau, P. L., Marth, W. J., Baumann, K., Edgerton, E. S., Shaw, S. L., Knipping, E. M., Worsnop, D. R., Jayne, J. T., Gold, A., and Surratt, J. D.: Real-Time Continuous Characterization of Secondary Organic Aerosol Derived from Isoprene Epoxydiols in Downtown Atlanta, Georgia, Using the Aerodyne Aerosol Chemical Speciation Monitor, Environ. Sci. Technol., 47, 5686-5694, doi:10.1021/es400023n, 2013.

Canagaratna, M. R., Jimenez, J. L., Kroll, J. H., Chen, Q., Kessler, S. H., Massoli, P., Hildebrandt Ruiz, L., Fortner, E., Williams, L. R., Wilson, K. R., Surratt, J. D., Donahue, N. M., Jayne, J. T., and Worsnop, D. R.: Elemental ratio measurements of organic compounds using aerosol mass spectrometry: characterization, improved calibration, and implications, Atmos. Chem. Phys., 15, 253-272, doi:10.5194/acp-15-253-2015, 2015.

Cappa, C. D. and Wilson, K. R.: Multi-generation gas-phase oxidation, equilibrium partitioning, and the formation and evolution of secondary organic aerosol, Atmos. Chem. Phys., 12, 9505-9528, doi:10.5194/acp-12-9505-2012, 2012.

Cappa, C. D., Zhang, X., Loza, C. L., Craven, J. S., Yee, L. D., and Seinfeld, J. H.: Application of the Statistical Oxidation Model (SOM) to Secondary Organic Aerosol formation from photooxidation of $\mathrm{C}_{12}$ alkanes, Atmos. Chem. Phys., 13, 1591-1606, doi:10.5194/acp-13-1591-2013, 2013.

Carlton, A. G., Bhave, P. V., Napelenok, S. L., Edney, E. O., Sarwar, G., Pinder, R. W., Pouliot, G. A., and Houyoux, M.: Model Representation of Secondary Organic Aerosol in CMAQv4.7, Environ. Sci. Technol., 44, 8553-8560, doi:10.1021/es100636q, 2010.

Chen, Q., Heald, C. L., Jimenez, J. L., Canagaratna, M. R., Qi, Z., Ling-Yan, H., Xiao-Feng, H., Campuzano-Jost, P., Palm, B. B., Poulain, L., Kuwata, M., Martin, S. T., Abbatt, J. P. D., Lee, A. K. Y., and Liggio, J.: Elemental composition of organic aerosol: the gap between ambient and laboratory measurements, Geophys. Res. Lett., 42, 4182-4189, doi:10.1002/2015gl063693, 2015.

Chhabra, P. S., Ng, N. L., Canagaratna, M. R., Corrigan, A. L., Russell, L. M., Worsnop, D. R., Flagan, R. C., and Seinfeld, J. H.: Elemental composition and oxidation of chamber organic aerosol, Atmos. Chem. Phys., 11, 8827-8845, doi:10.5194/acp-11-88272011, 2011.

De Gouw, J. and Jimenez, J. L.: Organic Aerosols in the Earth's Atmosphere, Environ. Sci. Technol., 43, 7614-7618, doi:10.1021/es9006004, 2009.

Docherty, K. S., Stone, E. A., Ulbrich, I. M., DeCarlo, P. F., Snyder, D. C., Schauer, J. J., Peltier, R. E., Weber, R. J., Murphy, S. M., Seinfeld, J. H., Grover, B. D., Eatough, D. J., and Jimenez, J. L.: Apportionment of Primary and Secondary Organic Aerosols in Southern California during the 2005 Study of Organic Aerosols in Riverside (SOAR-1), Environ. Sci. Technol., 42, 7655-7662, doi:10.1021/es8008166, 2008.

Docherty, K. S., Aiken, A. C., Huffman, J. A., Ulbrich, I. M., DeCarlo, P. F., Sueper, D., Worsnop, D. R., Snyder, D. C., Peltier, R. E., Weber, R. J., Grover, B. D., Eatough, D. J., Williams, B. J., Goldstein, A. H., Ziemann, P. J., and Jimenez, J. L.: The 2005 
Study of Organic Aerosols at Riverside (SOAR-1): instrumental intercomparisons and fine particle composition, Atmos. Chem. Phys., 11, 12387-12420, doi:10.5194/acp-11-12387-2011, 2011.

Dzepina, K., Volkamer, R. M., Madronich, S., Tulet, P., Ulbrich, I. M., Zhang, Q., Cappa, C. D., Ziemann, P. J., and Jimenez, J. L.: Evaluation of recently-proposed secondary organic aerosol models for a case study in Mexico City, Atmos. Chem. Phys., 9, 5681-5709, doi:10.5194/acp-9-5681-2009, 2009.

Dzepina, K., Cappa, C. D., Volkamer, R. M., Madronich, S., DeCarlo, P. F., Zaveri, R. A., and Jimenez, J. L.: Modeling the Multiday Evolution and Aging of Secondary Organic Aerosol During MILAGRO 2006, Environ. Sci. Technol., 45, 3496-3503, doi:10.1021/es103186f, 2011.

Ensberg, J. J., Hayes, P. L., Jimenez, J. L., Gilman, J. B., Kuster, W. C., de Gouw, J. A., Holloway, J. S., Gordon, T. D., Jathar, S., Robinson, A. L., and Seinfeld, J. H.: Emission factor ratios, SOA mass yields, and the impact of vehicular emissions on SOA formation, Atmos. Chem. Phys., 14, 2383-2397, doi:10.5194/acp14-2383-2014, 2014.

Ervens, B., Turpin, B. J., and Weber, R. J.: Secondary organic aerosol formation in cloud droplets and aqueous particles (aqSOA): a review of laboratory, field and model studies, Atmos. Chem. Phys., 11, 11069-11102, doi:10.5194/acp-1111069-2011, 2011.

Hayes, P. L., Ortega, A. M., Cubison, M. J., Froyd, K. D., Zhao, Y., Cliff, S. S., Hu, W. W., Toohey, D. W., Flynn, J. H., Lefer, B. L., Grossberg, N., Alvarez, S., Rappenglück, B., Taylor, J. W., Allan, J. D., Holloway, J. S., Gilman, J. B., Kuster, W. C., de Gouw, J. A., Massoli, P., Zhang, X., Liu, J., Weber, R. J., Corrigan, A. L., Russell, L. M., Isaacman, G., Worton, D. R., Kreisberg, N. M., Goldstein, A. H., Thalman, R., Waxman, E. M., Volkamer, R., Lin, Y. H., Surratt, J. D., Kleindienst, T. E., Offenberg, J. H., Dusanter, S., Griffith, S., Stevens, P. S., Brioude, J., Angevine, W. M., and Jimenez, J. L.: Organic aerosol composition and sources in Pasadena, California, during the 2010 CalNex campaign, J. Geophys. Res.-Atmos., 118, 9233-9257, doi:10.1002/jgrd.50530, 2013.

Hayes, P. L., Carlton, A. G., Baker, K. R., Ahmadov, R., Washenfelder, R. A., Alvarez, S., Rappenglück, B., Gilman, J. B., Kuster, W. C., de Gouw, J. A., Zotter, P., Prévôt, A. S. H., Szidat, S., Kleindienst, T. E., Offenberg, J. H., Ma, P. K., and Jimenez, J. L.: Modeling the formation and aging of secondary organic aerosols in Los Angeles during CalNex 2010, Atmos. Chem. Phys., 15, 5773-5801, doi:10.5194/acp-15-5773-2015, 2015.

Heald, C. L., Jacob, D. J., Park, R. J., Russell, L. M., Huebert, B. J., Seinfeld, J. H., Liao, H., and Weber, R. J.: A large organic aerosol source in the free troposphere missing from current models, Geophys. Res. Lett., 32, L18809, doi:10.1029/2005GL023831, 2005.

Hodzic, A., Aumont, B., Knote, C., Lee-Taylor, J., Madronich, S., and Tyndall, G.: Volatility dependence of Henry's law constants of condensable organics: Application to estimate depositional loss of secondary organic aerosols, Geophys. Res. Lett., 41, 4795-4804, doi:10.1002/2014g1060649, 2014.

Hodzic, A., Kasibhatla, P. S., Jo, D. S., Cappa, C., Jimenez, J. L., Madronich, S., and Park, R. J.: Rethinking the global secondary organic aerosol (SOA) budget: stronger production, faster removal, shorter lifetime, Atmos. Chem. Phys. Discuss., 15, 32413-32468, doi:10.5194/acpd-15-32413-2015, 2015.
Hu, W. W., Campuzano-Jost, P., Palm, B. B., Day, D. A., Ortega, A. M., Hayes, P. L., Krechmer, J. E., Chen, Q., Kuwata, M., Liu, Y. J., de Sá, S. S., McKinney, K., Martin, S. T., Hu, M., Budisulistiorini, S. H., Riva, M., Surratt, J. D., St. Clair, J. M., Isaacman-Van Wertz, G., Yee, L. D., Goldstein, A. H., Carbone, S., Brito, J., Artaxo, P., de Gouw, J. A., Koss, A., Wisthaler, A., Mikoviny, T., Karl, T., Kaser, L., Jud, W., Hansel, A., Docherty, K. S., Alexander, M. L., Robinson, N. H., Coe, H., Allan, J. D., Canagaratna, M. R., Paulot, F., and Jimenez, J. L.: Characterization of a real-time tracer for isoprene epoxydiols-derived secondary organic aerosol (IEPOX-SOA) from aerosol mass spectrometer measurements, Atmos. Chem. Phys., 15, 11807-11833, doi:10.5194/acp-15-11807-2015, 2015.

Jathar, S. H., Gordon, T. D., Hennigan, C. J., Pye, H. O. T., Pouliot, G., Adams, P. J., Donahue, N. M., and Robinson, A. L.: Unspeciated organic emissions from combustion sources and their influence on the secondary organic aerosol budget in the United States, P. Natl. Acad. Sci. USA, 111, 10473-10478, doi:10.1073/pnas.1323740111, 2014.

Jathar, S. H., Cappa, C. D., Wexler, A. S., Seinfeld, J. H., and Kleeman, M. J.: Multi-generational oxidation model to simulate secondary organic aerosol in a 3-D air quality model, Geosci. Model Dev., 8, 2553-2567, doi:10.5194/gmd-8-2553-2015, 2015a.

Jathar, S. H., Cappa, C. D., Wexler, A. S., Seinfeld, J. H., and Kleeman, M. J.: Simulating secondary organic aerosol in a regional air quality model using the statistical oxidation model - Part 1: Assessing the influence of constrained multi-generational ageing, Atmos. Chem. Phys., 16, 2309-2322, doi:10.5194/acp-162309-2016, 2016.

Kim, P. S., Jacob, D. J., Fisher, J. A., Travis, K., Yu, K., Zhu, L., Yantosca, R. M., Sulprizio, M. P., Jimenez, J. L., CampuzanoJost, P., Froyd, K. D., Liao, J., Hair, J. W., Fenn, M. A., Butler, C. F., Wagner, N. L., Gordon, T. D., Welti, A., Wennberg, P. O., Crounse, J. D., St. Clair, J. M., Teng, A. P., Millet, D. B., Schwarz, J. P., Markovic, M. Z., and Perring, A. E.: Sources, seasonality, and trends of southeast US aerosol: an integrated analysis of surface, aircraft, and satellite observations with the GEOS-Chem chemical transport model, Atmos. Chem. Phys., 15, 10411-10433, doi:10.5194/acp-15-10411-2015, 2015.

Kleeman, M. J. and Cass, G. R.: A 3-D Eulerian Source-Oriented Model for an Externally Mixed Aerosol, Environ. Sci. Technol., 35, 4834-4848, doi:10.1021/es010886m, 2001.

Kokkola, H., Yli-Pirilä, P., Vesterinen, M., Korhonen, H., Keskinen, H., Romakkaniemi, S., Hao, L., Kortelainen, A., Joutsensaari, J., Worsnop, D. R., Virtanen, A., and Lehtinen, K. E. J.: The role of low volatile organics on secondary organic aerosol formation, Atmos. Chem. Phys., 14, 1689-1700, doi:10.5194/acp-14-16892014, 2014.

Krechmer, J. E., Coggon, M. M., Massoli, P., Nguyen, T. B., Crounse, J. D., Hu, W., Day, D. A., Tyndall, G. S., Henze, D. K., Rivera-Rios, J. C., Nowak, J. B., Kimmel, J. R., Mauldin, R. L., Stark, H., Jayne, J. T., Sipilä, M., Junninen, H., Clair, J. M. S., Zhang, X., Feiner, P. A., Zhang, L., Miller, D. O., Brune, W. H., Keutsch, F. N., Wennberg, P. O., Seinfeld, J. H., Worsnop, D. R., Jimenez, J. L., and Canagaratna, M. R.: Formation of Low Volatility Organic Compounds and Secondary Organic Aerosol from Isoprene Hydroxyhydroperoxide Low-NO Oxidation, Environ. Sci. Technol., 49, 10330-10339, doi:10.1021/acs.est.5b02031, 2015. 
Lane, T. E., Donahue, N. M., and Pandis, S. N.: Effect of $\mathrm{NO}_{x}$ on Secondary Organic Aerosol Concentrations, Environ. Sci. Technol., 42, 6022-6027, doi:10.1021/es703225a, 2008a.

Lane, T. E., Donahue, N. M., and Pandis, S. N.: Simulating secondary organic aerosol formation using the volatility basis-set approach in a chemical transport model, Atmos. Environ., 42, 7439-7451, doi:10.1016/j.atmosenv.2008.06.026, 2008b.

Matsunaga, A. and Ziemann, P. J.: Gas-Wall Partitioning of Organic Compounds in a Teflon Film Chamber and Potential Effects on Reaction Product and Aerosol Yield Measurements, Aerosol Sci. Technol., 44, 881-892, doi:10.1080/02786826.2010.501044, 2010.

McVay, R. C., Cappa, C. D., and Seinfeld, J. H.: Vapor-Wall Deposition in Chambers: Theoretical Considerations, Environ. Sci. Technol., 48, 10251-10258, doi:10.1021/es502170j, 2014.

Murphy, B. N., Donahue, N. M., Fountoukis, C., and Pandis, S. N.: Simulating the oxygen content of ambient organic aerosol with the $2 \mathrm{D}$ volatility basis set, Atmos. Chem. Phys., 11, 7859-7873, doi:10.5194/acp-11-7859-2011, 2011.

Ng, N. L., Chhabra, P. S., Chan, A. W. H., Surratt, J. D., Kroll, J. H., Kwan, A. J., McCabe, D. C., Wennberg, P. O., Sorooshian, A., Murphy, S. M., Dalleska, N. F., Flagan, R. C., and Seinfeld, J. H.: Effect of $\mathrm{NO}_{x}$ level on secondary organic aerosol (SOA) formation from the photooxidation of terpenes, Atmos. Chem. Phys., 7, 5159-5174, doi:10.5194/acp-7-5159-2007, 2007a.

Ng, N. L., Kroll, J. H., Chan, A. W. H., Chhabra, P. S., Flagan, R. C., and Seinfeld, J. H.: Secondary organic aerosol formation from m-xylene, toluene, and benzene, Atmos. Chem. Phys., 7, 3909-3922, doi:10.5194/acp-7-3909-2007, 2007b.

Ng, N. L., Canagaratna, M. R., Jimenez, J. L., Chhabra, P. S., Seinfeld, J. H., and Worsnop, D. R.: Changes in organic aerosol composition with aging inferred from aerosol mass spectra, Atmos. Chem. Phys., 11, 6465-6474, doi:10.5194/acp-11-64652011, 2011.

Odum, J. R., Hoffmann, T., Bowman, F., Collins, D., Flagan, R. C., and Seinfeld, J. H.: Gas/particle partitioning and secondary organic aerosol yields, Environ. Sci. Technol., 30, 2580-2585, doi:10.1021/es950943+, 1996.

Pankow, J. F.: An absorption-model of the gas aerosol partitioning involved in the formation of secondary organic aerosol, Atmos. Environ., 28, 189-193, doi:10.1016/1352-2310(94)900949, 1994.

Pye, H. O. T., Pinder, R. W., Piletic, I. R., Xie, Y., Capps, S. L., Lin, Y.-H., Surratt, J. D., Zhang, Z., Gold, A., Luecken, D. J., Hutzell, W. T., Jaoui, M., Offenberg, J. H., Kleindienst, T. E., Lewandowski, M., and Edney, E. O.: Epoxide Pathways Improve Model Predictions of Isoprene Markers and Reveal Key Role of Acidity in Aerosol Formation, Environ. Sci. Technol., 47, 11056-11064, doi:10.1021/es402106h, 2013.

Robinson, A. L., Donahue, N. M., Shrivastava, M. K., Weitkamp, E. A., Sage, A. M., Grieshop, A. P., Lane, T. E., Pierce, J. R., and Pandis, S. N.: Rethinking organic aerosols: Semivolatile emissions and photochemical aging, Science, 315, 1259-1262, doi:10.1126/science.1133061, 2007.

Russell, A. R., Valin, L. C., and Cohen, R. C.: Trends in $\mathrm{OMI} \mathrm{NO}_{2}$ observations over the United States: effects of emission control technology and the economic recession, Atmos. Chem. Phys., 12, 12197-12209, doi:10.5194/acp-12-12197-2012, 2012.
SEAC4RS: Studies of Emissions and Atmospheric Composition, Clouds and Climate Coupling by Regional Surveys, NASA Langley Research Center, Hampton, VA, USA, doi:10.5067/Aircraft/SEAC4RS/Aerosol-TraceGas-Cloud, 2014.

Simon, H. and Bhave, P. V.: Simulating the Degree of Oxidation in Atmospheric Organic Particles, Environ. Sci. Technol., 46, 331339, doi:10.1021/es202361w, 2011.

Subramanian, R., Khlystov, A. Y., Cabada, J. C., and Robinson, A. L.: Positive and Negative Artifacts in Particulate Organic Carbon Measurements with Denuded and Undenuded Sampler Configurations, Aerosol Sci. Technol., 38, 27-48, doi:10.1080/02786820390229354, 2004.

The Visibility Information Exchange Web System (VIEWS 2.0): The Visibility Information Exchange Web System, Colorado State University, http://views.cira.colostate.edu/web/, last access: 11 February 2015.

Tkacik, D. S., Presto, A. A., Donahue, N. M., and Robinson, A. L.: Secondary Organic Aerosol Formation from Intermediate-Volatility Organic Compounds: Cyclic, Linear, and Branched Alkanes, Environ. Sci. Technol., 46, 8773-8781, doi:10.1021/es301112c, 2012.

Tsigaridis, K., Daskalakis, N., Kanakidou, M., Adams, P. J., Artaxo, P., Bahadur, R., Balkanski, Y., Bauer, S. E., Bellouin, N., Benedetti, A., Bergman, T., Berntsen, T. K., Beukes, J. P., Bian, H., Carslaw, K. S., Chin, M., Curci, G., Diehl, T., Easter, R. C., Ghan, S. J., Gong, S. L., Hodzic, A., Hoyle, C. R., Iversen, T., Jathar, S., Jimenez, J. L., Kaiser, J. W., Kirkevåg, A., Koch, D., Kokkola, H., Lee, Y. H, Lin, G., Liu, X., Luo, G., Ma, X., Mann, G. W., Mihalopoulos, N., Morcrette, J.-J., Müller, J.-F., Myhre, G., Myriokefalitakis, S., Ng, N. L., O’Donnell, D., Penner, J. E., Pozzoli, L., Pringle, K. J., Russell, L. M., Schulz, M., Sciare, J., Seland, Ø., Shindell, D. T., Sillman, S., Skeie, R. B., Spracklen, D., Stavrakou, T., Steenrod, S. D., Takemura, T., Tiitta, P., Tilmes, S., Tost, H., van Noije, T., van Zyl, P. G., von Salzen, K., Yu, F., Wang, Z., Wang, Z., Zaveri, R. A., Zhang, H., Zhang, K., Zhang, Q., and Zhang, X.: The AeroCom evaluation and intercomparison of organic aerosol in global models, Atmos. Chem. Phys., 14, 10845-10895, doi:10.5194/acp-1410845-2014, 2014.

Tsimpidi, A. P., Karydis, V. A., Zavala, M., Lei, W., Molina, L., Ulbrich, I. M., Jimenez, J. L., and Pandis, S. N.: Evaluation of the volatility basis-set approach for the simulation of organic aerosol formation in the Mexico City metropolitan area, Atmos. Chem. Phys., 10, 525-546, doi:10.5194/acp-10-525-2010, 2010.

Turpin, B. J. and Lim, H.-J.: Species Contributions to PM2.5 Mass Concentrations: Revisiting Common Assumptions for Estimating Organic Mass, Aerosol Sci. Technol., 35, 602-610, doi:10.1080/02786820119445, 2001.

Volkamer, R., Jimenez, J. L., San Martini, F., Dzepina, K., Zhang, Q., Salcedo, D., Molina, L. T., Worsnop, D. R., and Molina, M. J.: Secondary organic aerosol formation from anthropogenic air pollution: Rapid and higher than expected, Geophys. Res. Lett., 33, L17811, doi:10.1029/2006g1026899, 2006.

Worton, D. R., Surratt, J. D., LaFranchi, B. W., Chan, A. W. H., Zhao, Y., Weber, R. J., Park, J.-H., Gilman, J. B., de Gouw, J., Park, C., Schade, G., Beaver, M., Clair, J. M. S., Crounse, J., Wennberg, P., Wolfe, G. M., Harrold, S., Thornton, J. A., Farmer, D. K., Docherty, K. S., Cubison, M. J., Jimenez, J.-L., Frossard, 
A. A., Russell, L. M., Kristensen, K., Glasius, M., Mao, J., Ren, X., Brune, W., Browne, E. C., Pusede, S. E., Cohen, R. C., Seinfeld, J. H., and Goldstein, A. H.: Observational Insights into Aerosol Formation from Isoprene, Environ. Sci. Technol., 47, 11403-11413, doi:10.1021/es4011064, 2013.

Xu, L., Kollman, M. S., Song, C., Shilling, J. E., and Ng, N. L.: Effects of $\mathrm{NO}_{x}$ on the Volatility of Secondary Organic Aerosol from Isoprene Photooxidation, Environ. Sci. Technol., 48, 2253 2262, doi:10.1021/es404842g, 2014.

Xu, L., Guo, H., Boyd, C. M., Klein, M., Bougiatioti, A., Cerully, K. M., Hite, J. R., Isaacman-VanWertz, G., Kreisberg, N. M., Knote, C., Olson, K., Koss, A., Goldstein, A. H., Hering, S. V., de Gouw, J., Baumann, K., Lee, S.-H., Nenes, A., Weber, R. J., and $\mathrm{Ng}$, N. L.: Effects of anthropogenic emissions on aerosol formation from isoprene and monoterpenes in the southeastern United States, P. Natl. Acad. Sci. USA, 112, 37-42, doi:10.1073/pnas.1417609112, 2015a.

Xu, L., Suresh, S., Guo, H., Weber, R. J., and Ng, N. L.: Aerosol characterization over the southeastern United States using highresolution aerosol mass spectrometry: spatial and seasonal variation of aerosol composition and sources with a focus on organic nitrates, Atmos. Chem. Phys., 15, 7307-7336, doi:10.5194/acp15-7307-2015, 2015b.

Yeh, G. K. and Ziemann, P. J.: Gas-wall partitioning of oxygenated organic compounds: Measurements, structureactivity relationships, and correlation with gas chromatographic retention factor, Aerosol Sci. Technol., 49, 727-738, doi:10.1080/02786826.2015.1068427, 2015.

Zhang, Q., Jimenez, J. L., Canagaratna, M. R., Allan, J. D., Coe, H., Ulbrich, I., Alfarra, M. R., Takami, A., Middlebrook, A. M., Sun, Y. L., Dzepina, K., Dunlea, E., Docherty, K., DeCarlo, P. F., Salcedo, D., Onasch, T., Jayne, J. T., Miyoshi, T., Shimono, A., Hatakeyama, S., Takegawa, N., Kondo, Y., Schneider, J., Drewnick, F., Borrmann, S., Weimer, S., Demerjian, K., Williams, P., Bower, K., Bahreini, R., Cottrell, L., Griffin, R. J., Rautiainen, J., Sun, J. Y., Zhang, Y. M., and Worsnop, D. R.: Ubiquity and dominance of oxygenated species in organic aerosols in anthropogenically-influenced Northern Hemisphere midlatitudes, Geophys. Res. Lett., 34, L13801, doi:10.1029/2007GL029979, 2007.
Zhang, X., Cappa, C. D., Jathar, S. H., McVay, R. C., Ensberg, J. J., Kleeman, M. J., and Seinfeld, J. H.: Influence of vapor wall loss in laboratory chambers on yields of secondary organic aerosol, P. Natl. Acad. Sci. USA, 111, 5802-5807, doi:10.1073/pnas.1404727111, 2014.

Zhang, X., Schwantes, R. H., McVay, R. C., Lignell, H., Coggon, M. M., Flagan, R. C., and Seinfeld, J. H.: Vapor wall deposition in Teflon chambers, Atmos. Chem. Phys., 15, 4197-4214, doi:10.5194/acp-15-4197-2015, 2015.

Zhao, Y., Hennigan, C. J., May, A. A., Tkacik, D. S., de Gouw, J. A., Gilman, J. B., Kuster, W. C., Borbon, A., and Robinson, A. L.: Intermediate-Volatility Organic Compounds: A Large Source of Secondary Organic Aerosol, Environ. Sci. Technol., 48, 1374313750, doi:10.1021/es5035188, 2014.

Ziemann, P. J. and Atkinson, R.: Kinetics, products, and mechanisms of secondary organic aerosol formation, Chem. Soc. Rev., 41, 6582-6605, doi:10.1039/C2CS35122F, 2012.

Zotter, P., El-Haddad, I., Zhang, Y., Hayes, P. L., Zhang, X., Lin, Y.-H., Wacker, L., Schnelle-Kreis, J., Abbaszade, G., Zimmermann, R., Surratt, J. D., Weber, R., Jimenez, J. L., Szidat, S., Baltensperger, U., and Prévôt, A. S. H.: Diurnal cycle of fossil and nonfossil carbon using radiocarbon analyses during CalNex, J. Geophys. Res.-Atmos., 119, 6818-6835, doi:10.1002/2013JD021114, 2014. 